\title{
Impacts of the Atlantic Equatorial Mode in a warmer climate
}

\author{
Elsa Mohino • Teresa Losada
}

Received: 7 July 2014 / Accepted: 7 January 2015 / Published online: 20 January 2015

(C) The Author(s) 2015. This article is published with open access at Springerlink.com

\begin{abstract}
The main source of sea surface temperature (SST) variability in the Tropical Atlantic at interannual time scales is the Equatorial Mode or Atlantic El Niño. It has been shown to affect the adjacent continents and also remote regions, leading to a weakened Indian Monsoon and promoting La Niña-type anomalies over the Pacific. However, its effects in a warmer climate are unknown. This work analyses the impact of the Equatorial Mode at the end of the twenty first century by means of sensitivity experiments with an atmosphere general circulation model. The prescribed boundary conditions for the future climate are based on the outputs from models participating in the coupled model intercomparison project-phase V. Our results suggest that even if the characteristics of the Equatorial Mode at the end of the twenty first century remained equal to those of the twentieth century, there will be an eastward shift of the main rainfall positive anomalies in the Tropical Atlantic and a weakening of the negative rainfall anomalies over the Asian monsoon due to the change in climatological SSTs. We also show that extratropical surface temperature anomalies over land related to the mode will change in regions like Southwestern Europe, East Australia, Asia or North America due to the eastward shift of the sea level pressure systems and related surface winds.
\end{abstract}

Keywords Tropical Atlantic variability $\cdot$ Atlantic Equatorial Mode $\cdot$ Climate change $\cdot$ Atmosphere general circulation model $(\mathrm{AGCM}) \cdot$ Interannual variability

E. Mohino $(\bowtie) \cdot$ T. Losada

Dpto. Física de la Tierra, Astronomía y Astrofísica I,

Facultad Ciencias Físicas, Universidad Complutense de Madrid,

Plaza de Ciencias, 1, 28040 Madrid, Spain

e-mail: emohino@fis.ucm.es

\section{Introduction}

Interannual variability in the tropical Atlantic basin is dominated by the Equatorial Mode (Zebiak 1993). Its signature on sea surface temperature (SST) anomalies is a warming of the tropical eastern Atlantic basin related to a deepening of the thermocline (Carton and Huang 1994; Carton et al. 1996). The mode starts in Angola/Benguela region and propagates west and north via Rossby waves (Polo et al. 2008).

The Equatorial Mode is also known as the Atlantic El Niño due to its similarities with its Pacific counterpart. The underlying mechanism for this mode is the Bjerknes feedback (Chang et al. 2006; Keenlyside and Latif 2007; Jansen et al. 2009), by which a warm anomaly in the eastern equatorial basin weakens the trade winds, which, in turn, reduce upwelling and deepen the thermocline in the east causing further warming (Bjerknes 1969). Both El Niño events are well described by the recharge oscillator model (Jansen et al. 2009). However, the Atlantic Equatorial Mode is further damped than the Pacific El Niño (Zebiak 1993; Lübbecke and McPhaden 2013). The Atlantic Equatorial Mode is tightly tied to the seasonal cycle but, unlike the Pacific El Niño, it shows maximum SST anomalies in boreal summer.

The Atlantic Equatorial Mode is known to affect interannual climate variability over adjacent and remote regions. A positive phase of the mode leads to increases of rainfall over the Gulf of Guinea and reductions over the Sahel (Janicot et al. 1998; Vizy and Cook 2002; Giannini et al. 2005; Losada et al. 2010a; Mohino et al. 2011, among others). This dipole of rainfall over West Africa is established through a reduction of the surface temperature gradient that weakens the monsoon flow and shifts it southwards (Janicot et al. 1998; Losada et al. 2010a). On the other side of the basin, rainfall over the brazilian Nordeste region is 
increased by the Equatorial Mode through a southward shift in the location of the Intertropical Convergence Zone (Giannini et al. 2004). Garcia-Serrano et al. (2011) also report impacts over central Europe due to poleward Rossby wave propagation. In turn, Losada et al. (2012) suggest that it can also affect Mediterranean rainfall during boreal summer, although differently depending on the years taken into account.

Away from the Atlantic basin, Kucharski et al. (2009) and Losada et al. (2010b) argue that the Equatorial Mode promotes anomalous rising over the Equatorial Atlantic and anomalous subsidence over the rest of the tropics. This can lead to a weakening of the Asian monsoon (Kucharski et al. 2008; Losada et al. 2010b) and also explain the reduction in the anticorrelation between ENSO and the Indian monsoon rainfall (Kucharski et al. 2007). On the Pacific basin the anomalous subsidence has been shown to favour La Niña development in the last part of the twentieth century (Rodriguez-Fonseca et al. 2009; Ding et al. 2012), which can have impacts for ENSO prediction (Keenlyside et al. 2013). However, to our knowledge, there is no study on the possible changes of these impacts in a future warmer climate, which is the main aim of this work.

The usual tool to explore climate change for the next century are general circulation models (GCMs), which couple several components of the climate system, including the atmosphere and the ocean. These GCMs respond to prescribed time-varying concentrations of various atmospheric constituents like greenhouse gases (Taylor et al. 2011). However, GCMs are known to have serious systematic biases which are common to many models (Wang et al. 2014). Ashfaq et al. (2011) show that these SST biases can substantially affect the simulated tropical rainfall response to climate change. One of the regions with severe biases is the tropical southeastern Atlantic, which shows a warm bias with a magnitude comparable to the projected climate change of SSTs in the area (Fig. 1). This bias has been shown to hinder the predictability skill in the region (Stockdale et al. 2006). Richter et al. (2014) showed that there has been very modest improvement in reducing this bias in the last years. In both coupled model intercomparison projects phase 3 (CMIP3) and phase 5 (CMIP5) most models show a zonal gradient of equatorial SSTs in boreal summer that is reversed with respect to the observations (Richter et al. 2014). The bias seems related to weaker than observed easterlies in the previous boreal spring, which deepen the thermocline in the east and lead to its shoaling in the west (Richter et al. 2012, 2014). Part of the weak easterlies seem to come from the atmospheric part of the model through less rainfall than observed over South America and more rainfall than observed over Equatorial Africa and a southward location of the ITCZ (Richter and Xie 2008; Richter et al. 2012). In addition, very few current GCMs are able (a) Summer SST biases

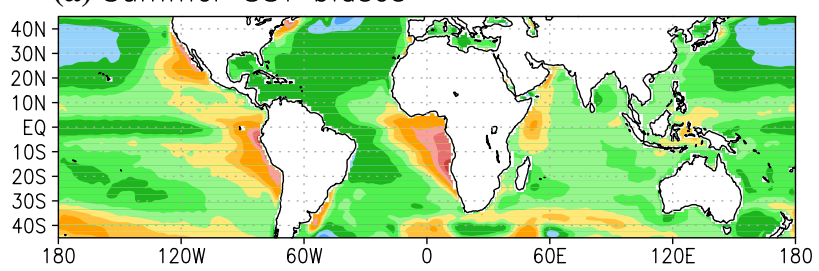

(b) Summer SST climate change

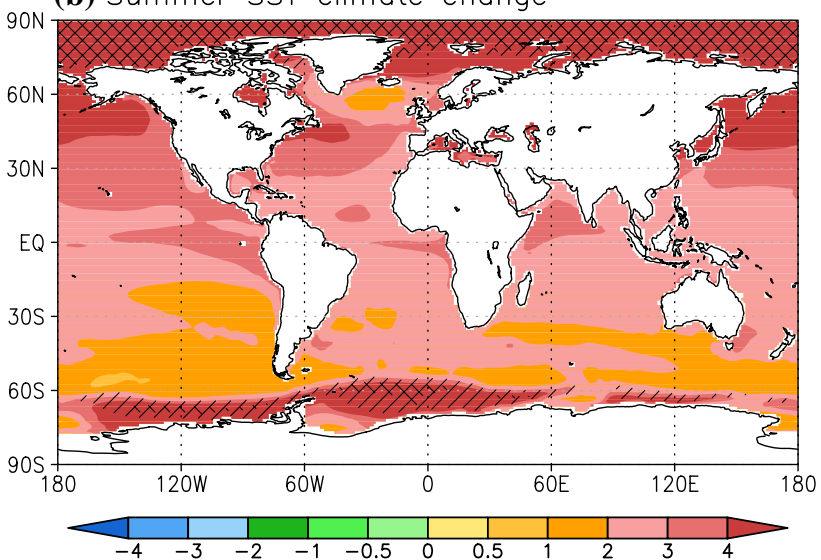

Fig. 1 a Summer (July to September) SST bias $\left({ }^{\circ} \mathrm{C}\right)$ averaged over the 11 CMIP5 models used (see Table 2). b Average summer (July to September) change in SST $\left({ }^{\circ} \mathrm{C}\right.$, shaded) and sea ice concentration (hatched) between the period 2071-2100 and the period 19712000 simulated by the CMIP5 models used. For sea ice concentration regions with a reduction between 15 and 30 points are simply hatched, while those with a reduction above 30 points are double hatched

to simulate a realistic Atlantic Equatorial Mode (Richter et al. 2014) and coupled models fail to simulate many of the observed teleconnections of the Tropical Atlantic SSTs, possibly due to model climatological biases, especially over the Tropical Atlantic (Barimalala et al. 2012).

In this work we aim at diagnosing the possible changes in the impacts of the Atlantic Equatorial Mode in a warmer climate. On the one hand, these changes could be due to modifications in the characteristics of the mode. On the other, changes in the background state of the climate system could alter the impacts of the mode through the modification of climatological features relevant for the teleconnections with remote regions. The presence of severe biases in the Tropical Atlantic and the difficulty for GCMs to simulate a realistic Equatorial Mode and its impact hinder the study of changes in the characteristics of the mode. However, GCM projected SST changes can be used to evaluate the change of the impact of the mode due to a modification of the background state. This is the approach we use in this work. We analyze the change of the impact of the Atlantic Equatorial Mode by means of sensitivity experiments performed with the SPEEDY Atmospheric General Circulation Model (AGCM) that use as boundary conditions SSTs 
Table 1 Set of the main simulations performed (first column), name of the experiments (second column), climatological (third column) and anomalous (fourth column) SSTs used as boundary conditions,

\begin{tabular}{llllll}
\hline Set & Name & Climatological SSTs & SST anomalies & CO $_{2}$ concentration & Sea ice concentration \\
\hline Present & Present_clim & $1971-2000$ & No & Present & $1971-2000$ \\
& Present_pos & $1971-2000$ & ATL mode+ & Present & $1971-2000$ \\
& Present_neg & $1971-2000$ & ATL mode- & Present & $1971-2000$ \\
Future & Future_clim & $2071-2100$ RCP85 & No & $2.9 *$ present & $2071-2100$ RCP85 \\
& Future_pos & $2071-2100$ RCP85 & ATL mode+ & $2.9 *$ present & $2071-2100$ RCP85 \\
& Future_neg & $2071-2100$ RCP85 & ATL mode- & $2.9 *$ present & $2071-2100$ RCP85 \\
\hline
\end{tabular}

reference $\mathrm{CO}_{2}$ concentration (fifth column) and sea ice concentration used as boundary conditions (sixth column) for the experiment from the HadISST1 reconstruction (Rayner et al. 2003) and projected SST changes given by $11 \mathrm{GCM}$ sarticipating in CMIP5 (Taylor et al. 2011).

The study is organized in four sections. In Sect. 2 we describe the data and model used, as well as the experimental design followed. The main results of the work are presented in Sect. 3. Finally, Sect. 4 provides a summary of the results and the main conclusions of the study.

\section{Data and methods}

\subsection{Observations}

HadISST1 (Rayner et al. 2003) dataset is used in this work. It is a reconstructed dataset of SST and sea ice concentration with a horizontal resolution of $1^{\circ}$ in latitude and longitude and global coverage. It spans the period 1870 to present with a time resolution of 1 month. We also use monthly mean precipitation estimates over land from the University of East Anglia Climate Research Unit (CRU), version TS3.1 (Mitchel and Jones 2005).

\subsection{Models}

Associated with the fifth report of the Intergovernmental Panel on Climate Change (IPCC 2013), there is a coordinated project known as the fifth phase of the Coupled Model Intercomparison Project (CMIP5) that involves some of the most important modelling groups in the world. This project provides a framework for coordinated modelling experiments with state-of-the-art general circulation models (GCM) (Taylor et al. 2011). Two sets of long-term simulations were used from CMIP5: historical and future projection RCP8.5. The former is forced by observed atmospheric changes and typically covers the period from the mid-nineteenth century to present. The RCP8.5 future projection used is representative of a high emission scenario, with an approximative radiative forcing of $8.5 \mathrm{Wm}^{-2}$ at the end of the twenty first century. It prescribes a $\mathrm{CO}_{2}$ and $\mathrm{CH}_{4}$ concentration of close to three times greater (2.9 $\mathrm{CO}_{2}$ and $2.7 \mathrm{CH}_{4}$ ) at the end of the twenty first century than at the end of the twentieth.

In this work we use the SPEEDY AGCM model version 40 run with a spectral truncation at a total wavenumber 30 (approximate resolution of $3.8^{\circ}$ in latitude and longitude) and eight vertical levels. Details for this model can be found in Molteni (2003) and Kucharski et al. (2007). Despite some biases in the representation of the summer Asian monsoon, the model presents a realistic distribution of boreal summer rainfall over the East Pacific and the Tropical Atlantic (Molteni 2003). The model has been extensively used in climate studies regarding the teleconnections of the Tropical Atlantic (e.g. Martín-Rey et al. 2012; Barimalala et al. 2012; Kucharski et al. 2007, 2008, 2009, 2011; Losada et al. 2012; Rodriguez-Fonseca et al. 2009). Rauscher et al. (2011) and Herceg Bulic et al. (2012) also argue that SPEEDY can be used in climate change impact studies as it is capable of simulating similar anomalies than those from complex coupled models given the appropriate boundary conditions.

\subsection{Experimental design}

\subsubsection{Climatology}

In this work we analyze the impact of the Equatorial Mode in two different periods: the period 1971-2000, which we name hereafter the "present climate" and the period 2071-2100, which we name hereafter "future climate". To simulate the present climate, we use SSTs and sea ice concentrations averaged in the period 1971-2000 from the HadISST1 database (Rayner et al. 2003). This is labeled as 1971-2000 in Table 1. In the present climate simulations, the absorption coefficient in the $\mathrm{CO}_{2}$ band is fixed to be consistent with late-twentieth century $\mathrm{CO}_{2}$ concentrations.

To simulate the future climate we rely on simulations performed by some of the models participating in CMIP5 historical and RCP8.5 experiments. However, Ashfaq et al. (2011) showed that GCM SST biases can greatly affect 
Table 2 Models used to build the SST and sea ice concentration boundary conditions for the future climate (first column), modelling institution (second column), country (third column), approximate horizontal resolution (fourth column) and reference (fifth column)

\begin{tabular}{|c|c|c|c|c|}
\hline Model name & Modeling centre (or group) & Country & Resolution (Lon $\times$ Lat) & References \\
\hline CNRM-CM5 & $\begin{array}{l}\text { Centre National de Recherches Meteorologiques/Centre } \\
\text { Europeen de Recherche et Formation Avancees en Calcul } \\
\text { Scientifique }\end{array}$ & France & $1.4^{\circ}$ & Voldoire et al. (2013) \\
\hline GISS-E2-R & NASA Goddard Institute for Space Studies & USA & $2.5^{\circ} \times 2.0^{\circ}$ & Schmidt et al. (2014) \\
\hline HadGEM2-ES & Met Office Hadley Centre & UK & $1.9^{\circ} \times 1.3^{\circ}$ & Martin et al. (2011) \\
\hline CCSM4 & National Center for Atmospheric Research & USA & $1.3^{\circ} \times 0.9^{\circ}$ & Gent et al. (2011) \\
\hline CSIRO-Mk3-6-0 & $\begin{array}{l}\text { Commonwealth Scientific and Industrial Research Organi- } \\
\text { sation in collaboration with the Queensland Climate } \\
\text { Change Centre of Excellence }\end{array}$ & Australia & $1.9^{\circ}$ & Rotstayn et al. (2012) \\
\hline inmem4 & Institute for Numerical Mathematics & Russia & $2.0^{\circ} \times 1.5^{\circ}$ & Volodin et al. (2010) \\
\hline IPSL-CM5A-LR & Institut Pierre-Simon Laplace & France & $3.8^{\circ} \times 1.9^{\circ}$ & Dufresne et al. (2013) \\
\hline MIROC-ESM-CHEM & $\begin{array}{l}\text { Japan Agency for Marine-Earth Science and Technology, } \\
\text { Atmosphere and Ocean Research Institute (The Univer- } \\
\text { sity of Tokyo), and National Institute for Environmental } \\
\text { Studies }\end{array}$ & Japan & $2.8^{\circ}$ & Watanabe et al. (2011) \\
\hline MPI-ESM-LR & Max Planck Institute for Meteorology (MPI-M) & Germany & $1.9^{\circ}$ & Giorgetta et al. (2013) \\
\hline MRI-CGCM3 & Meteorological Research Institute & Japan & $1.1^{\circ}$ & Yukimoto et al. (2011) \\
\hline NorESM1-M & Norwegian Climate Centre & Norway & $2.5^{\circ} \times 1.9^{\circ}$ & Bentsen et al. (2012) \\
\hline
\end{tabular}

projections of climate change. To avoid the effect of these biases we use a similar approach to the one proposed in Patricola and Cook (2011), Rauscher et al. (2011) and Chung et al. (2014): for both, SST and sea ice concentration, we estimate the future climatologies as the addition of the changes simulated by the models in each variable to the present climatologies derived from HadISST1 dataset. This is labeled as 2071-2100 in Table 1. The SST and sea ice concentration changes are calculated as the multi-model average difference between the climatologies simulated by each model for the present and future climates. Figure $1 \mathrm{~b}$ illustrates the average change in climatological summer SSTs simulated by the CMIP5 models. For consistency reasons, the absorption coefficient in the $\mathrm{CO}_{2}$ band in the future climate simulations is fixed as 2.9 times the one used in the present climate simulations. In total, 11 models were selected based on the availability of their historical and RCP8.5 simulations at the time of analysis (Table 2). We also discarded different versions of a same model.

\subsubsection{Definition of the Atlantic Equatorial Mode}

To define the SST anomalies corresponding to the Equatorial Mode we calculate the empirical orthogonal functions (EOFs) of the June-July-August-September (JJAS) anomalies of SST for the Atlantic ocean covering the latitudes $30^{\circ} \mathrm{S}$ to $20^{\circ} \mathrm{N}$ and for the period $1971-2000$. SST data is detrended previously to the EOF calculation. Then, we select those years in which the principal component (PC) of the first EOF is larger (smaller) than one $(-1)$ standard deviation for the 4 months. This gives us 1973, 1984, 1987, 1998 as positive years and 1976, 1982, 1992 as negative years. We calculate the anomalous pattern of the Equatorial Mode for the model experiments as the difference between the positive and negative years. Finally, to avoid discontinuities in the SST fields, we apply a linear decrease of the SST anomalies in a $10^{\circ}$ band polewards from $30^{\circ} \mathrm{S}$ and $20^{\circ} \mathrm{N}$.

In Fig. 2a we show the summer (July to September) mean SST anomalies corresponding to the Equatorial Mode that we use in the AGCM experiments. The warm anomalies cover the whole equatorial Atlantic from March to December, with the maximum warming during boreal summer, especially during the months of July and August (not shown). The analysis presented in this paper focuses on the boreal summer season, defined hereafter as the average in July, August and September.

\subsubsection{AGCM experiments}

Table 1 summarizes the simulations performed to evaluate the impact of the Equatorial Mode in the present and future climates. Each simulation consists of a 60 -year run started from an atmosphere at rest. The first 10 years of simulation are discarded. We perform two sets of simulations, one for the present climate and another one for the future one. Each set is composed by three simulations, one for the positive phase of the mode, one for the negative and one for the 
(a) SST composite
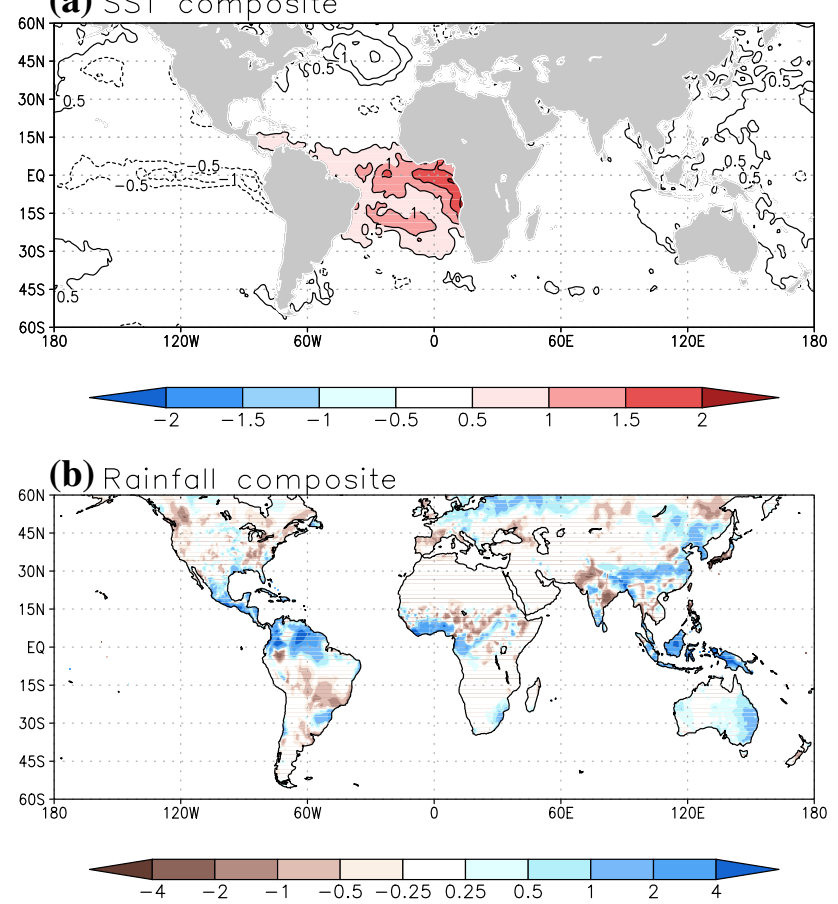

Fig. 2 Composite of summer (July to September) anomalies of SSTs $\left({ }^{\circ} \mathrm{C}\right)$ (a) and CRUTS3.1 rainfall (mm/day) (b) corresponding to the years chosen to define the Equatorial Mode (see text details for the definition). SST anomalies used in the positive and negative experiments are restricted to the Atlantic basin between $30^{\circ} \mathrm{S}$ and $20^{\circ} \mathrm{N}$ with a linear decrease in the $10^{\circ}$ poleward band and are highlighted in shaded in (a)

climatology. The SST boundary conditions for each simulation are obtained by adding the 12-month SST anomalies representative of the Equatorial Mode phase (positive, negative or no mode) to the climatological SSTs corresponding to the present and future climates (Table 1). In this work we focus on the linear part of the impact of the Equatorial Mode and estimate it as the difference between the positive and negative simulations averaged over the last 50 years of the simulations for a given set. To test whether this difference is statistically significant, a two-tailed $t$ test is used at a significance level of alpha 0.05 . The main conclusions of the work hold when defining the impact in terms of the positive minus control runs or the negative minus control ones (not shown).

To evaluate the change of impact, we subtract the difference between the positive and negative simulations in the present climate set to the same difference obtained in the future climate set. To test the significance of this change, we use the Wilcoxon-Mann-Whitney rank-sum test. This is a non parametric test that evaluates the difference in location of two independent samples. Details of the test can be found in Wilks (2005). Again, we use a significance level of alpha 0.05 . (a) Present 71-00 Eq. Mode impact

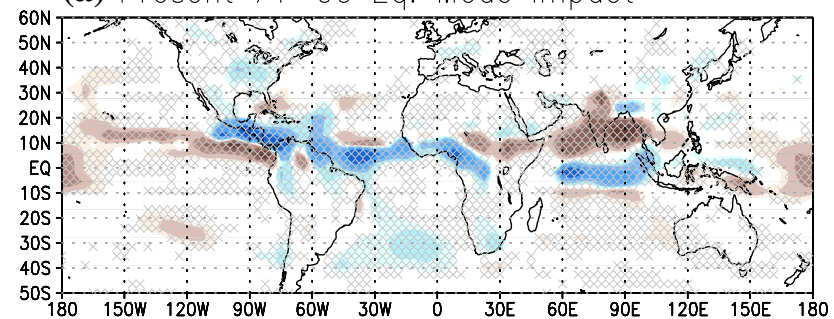

(b) Future rcp85 Eq. Mode impact

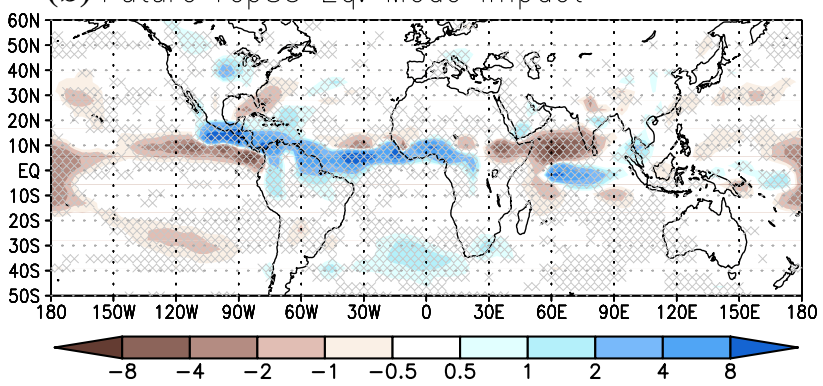

(c) Change (future - present) Eq. Mode impact

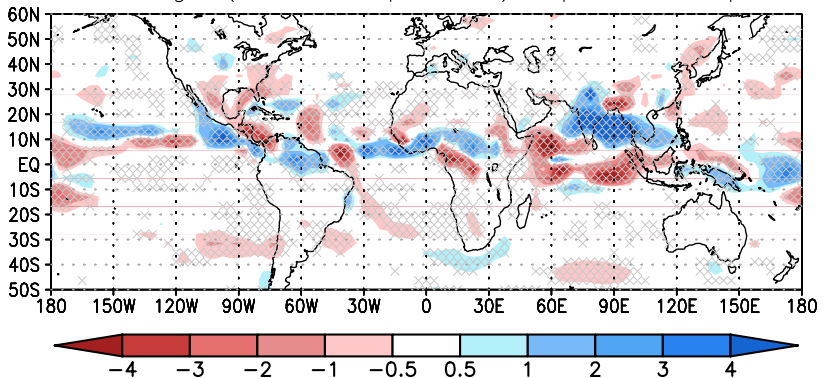

Fig. 3 Impact of the Equatorial Mode on summer (July to September) rainfall (mm/day) in: a present; b future climate. c Difference between the impact for the future and the present simulations. Regions where differences are statistically significant $($ alpha $=0.05)$ are marked with crosses

\section{Results}

\subsection{Tropics}

We begin our analysis by focusing on the tropical response to the Equatorial Mode. In Fig. 3 we show the impact of the mode under present conditions, future conditions and the change between these impacts. We focus on the boreal summer season (July to September), when the amplitude of the Equatorial Mode is highest.

Under the present climate, the model shows a rainfall response to the mode consistent with previous studies. In the Tropical Atlantic a dipole of rainfall is present with an anomalous increase below $10^{\circ} \mathrm{N}$ and an anomalous decrease above this latitude. Over the surrounding continents, an increase of rainfall over the Guinea Gulf and Northern Brazil is simulated, while significant rainfall deficits are present over East Africa, in accordance with 
Giannini et al. (2004) and Losada et al. (2010a). Over Central America, rainfall is enhanced while it is reduced over the Florida Peninsula. Such anomalies are consistent with the precipitation response shown by Wang et al. (2008) in their study on the atmospheric impact of the Atlantic Warm Pool and could, thus, be related to the anomalous warming of the southern part of the Atlantic Warm Pool that accompanies the Equatorial Mode in our simulations (Fig. 2a). In the Indian basin there are negative rainfall anomalies over the Asian monsoon and positive ones over the Equatorial Indian Ocean (Fig. 3a). These anomalies are related together by a Hadley-type cell (not shown), as suggested by Losada et al. (2010b). Over the Tropical Pacific, there is reduced rainfall over the dateline in connection to a reinforcement of the trades (not shown), which is consistent with previous studies (Rodriguez-Fonseca et al. 2009; Losada et al. 2010b).

The simulated tropical rainfall anomalies over land show consistency with observations, especially over Africa and Central and South America (Figs. 2b, 3a). However, the model does not simulate the positive anomalies of rainfall over the Maritime continent shown in observations. Such discrepancy is related to the SST anomalies over the Pacific basin that were not used in our experiments (Fig. 2a) and which reduce rainfall over the central Pacific and enhance it over the Maritime Continent (not shown).

In the future climate the impact of the Equatorial Mode is increased in the Tropical Atlantic basin, with enhanced rainfall over the Amazonian basin and over a zonal band between the Equator and $10^{\circ} \mathrm{N}$ spanning the Atlantic ocean east of $35^{\circ} \mathrm{W}$, and West Africa (Fig. 3b, c). This is consistent with increased convergence at low-levels in those areas (Fig. 4c) and a more negative anomaly of the velocity potential at $200 \mathrm{hPa}$ over the Tropical North Atlantic off the South America coast (not shown). The maximum anomalous rainfall and low-level divergence are shifted eastwards from approximately $40^{\circ} \mathrm{W}$ in the present climate to $30^{\circ} \mathrm{W}$ in the future one (Figs. 3, 4). This change in the impact of the Equatorial Mode can be related to the increase in SSTs over the Tropical Atlantic from the present to the future. In Fig. 5a, b we show that the area where the SST approximate threshold of $28{ }^{\circ} \mathrm{C}$ for deep convection (Zhang 1993; Sud et al. 1999) is reached is amplified in the Tropical Atlantic basin in a future climate, including much of its eastern part (Fig. 5b). This change of climatological SSTs could promote the increase and shift towards the north and east of the climatological low-level convergence (Fig. 4d, e) and associated rainfall over the North Tropical Atlantic (not shown). In this future scenario, an additional SST anomaly over the Tropical Atlantic related to the Atlantic Equatorial Mode has an increased local impact that is shifted to the east of the basin.
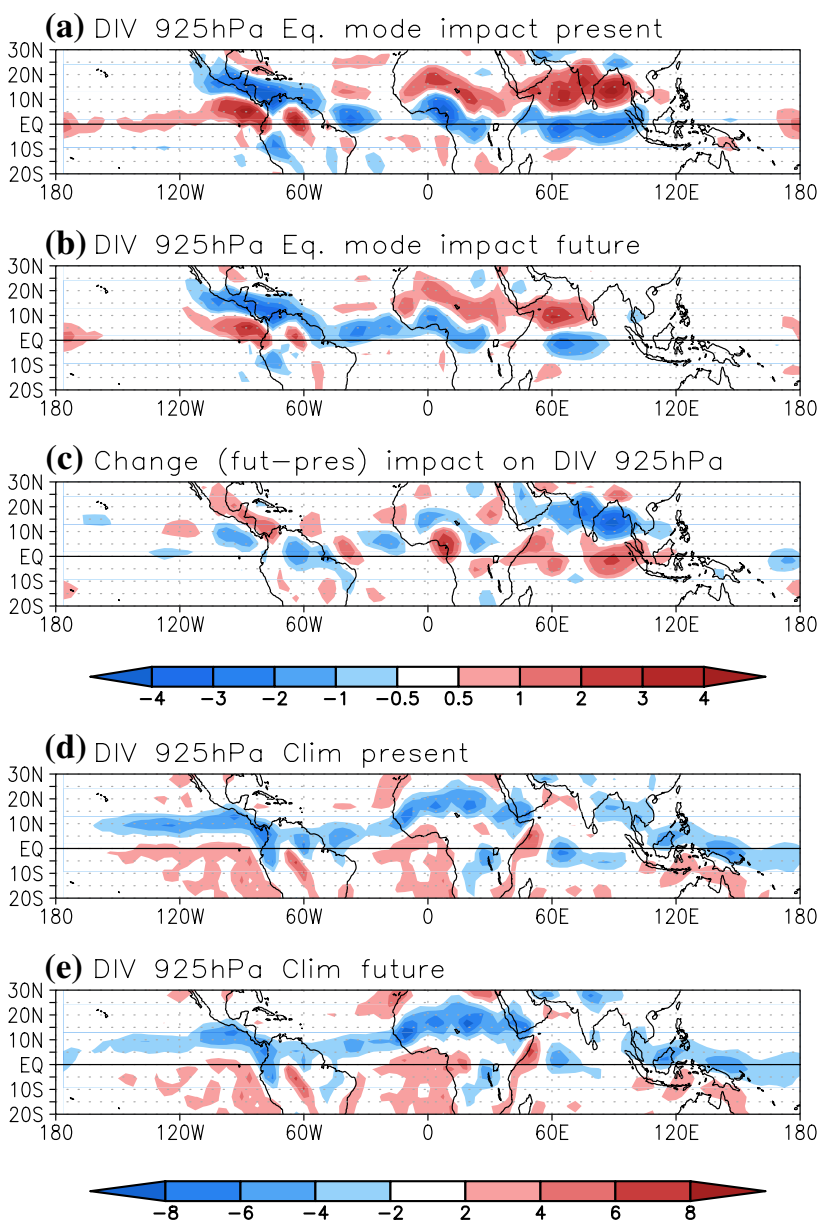

Fig. 4 Impact of the Equatorial Mode on summer (July to September) divergence $\left(10^{-6} \mathrm{~s}^{-1}\right)$ at $925 \mathrm{hPa}$ in the present climate (a) and future climate (b) and difference between them (c). Climatological divergence at $925 \mathrm{hPa}$ in the present climate (d) and future climate (e)

However, the main differences in rainfall between the present and future simulations are found in the tropical Indian Ocean. The negative anomalies of rainfall located over the Bay of Bengal and the Indian Continent weaken, while those located over the western Indian Ocean are reinforced (Fig. 3). This change contradicts the results of previous works (Kucharski et al. 2008; Losada et al. 2010b); following those previous results one would expect that an increase in low level convergence over the Tropical Atlantic and West Africa would lead to an increase in low level divergence over the Indian Peninsula and Bay of Bengal. Nevertheless, in our results the impact of the Equatorial Mode in a future climate shows a weakening in the low level divergence over that region (Fig. 4c). The explanation for this apparent inconsistency can be related to the change in climatological divergence (Fig. 4 d, e): In the present simulation there is a region of low level convergence over the Bay of Bengal related to the Asian Monsoon. In the future climatology this convergence is weakened, while 
(a) Present 71-00 Eq. Mode impact st

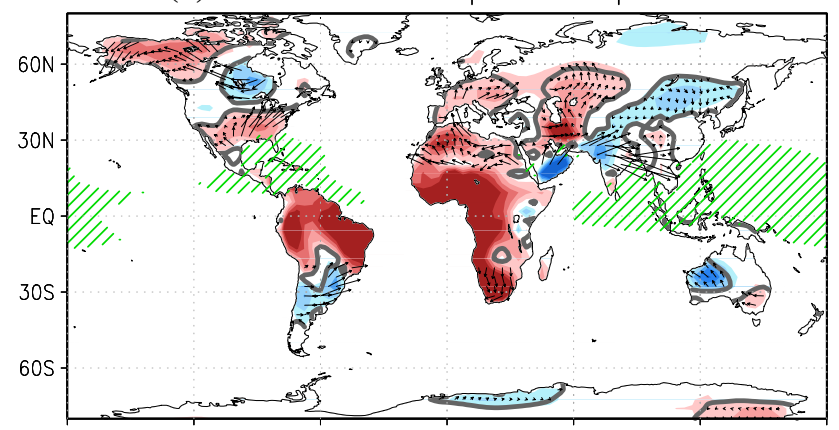

(b) Future rcp85 Eq. Mode impact st

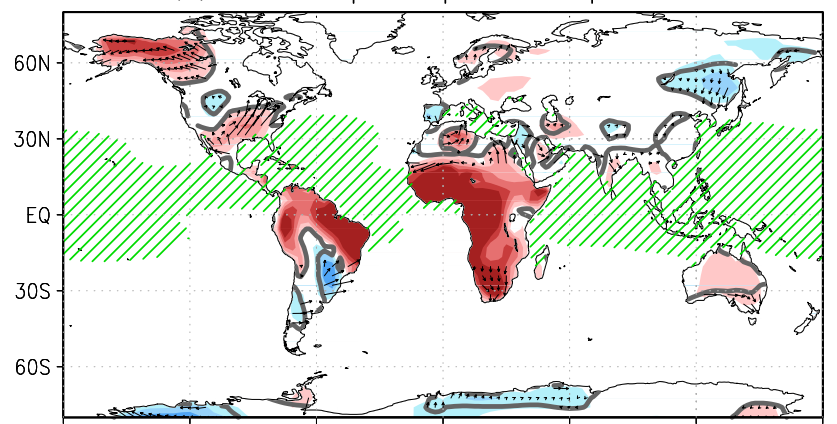

(c) Change (future - present) Eq. Mode impact st

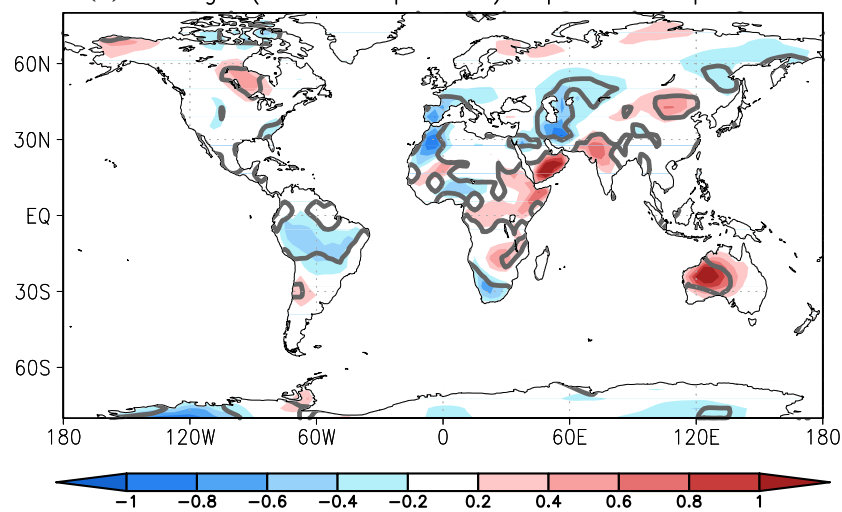

Fig. 5 Impact of the Equatorial Mode on summer (July to September) land surface temperature $\left({ }^{\circ} \mathrm{C}\right)$ in the present (a) and future climate (b), and difference between them (c). Impact of the Equatorial Mode on summer (July to September) mean sea level pressure ( $\mathrm{hPa}$ ) in the present (d) and future climate (e) and difference between them (f). Thick gray contours mark the statistically significant regions

the convergence over the north of India is intensified. To explain such a change in the climatological divergence, we look into the characteristics of the climatological SSTs over the Indian Ocean, for the present and future climates. In addition to a general increase in the temperature of the whole basin, the main gradients of SST do not change in the western part of the Ocean, while they do in its eastern part (Fig. 6). In the present conditions, there is a relative maximum (minimum) of SST north (south) of $10^{\circ} \mathrm{N}$ over the Bay of Bengal (Fig. 6a). Such maximum would be (d) Present 71-00 Eq. Mode impact mslp

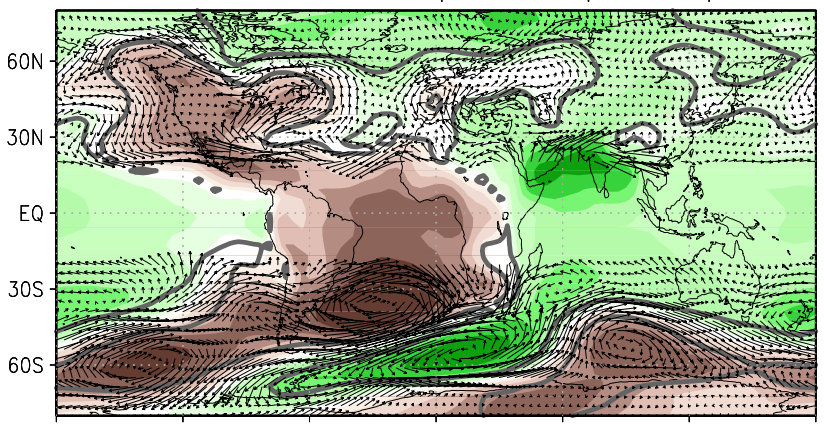

(e) Future rcp85 Eq. Mode impact mslp

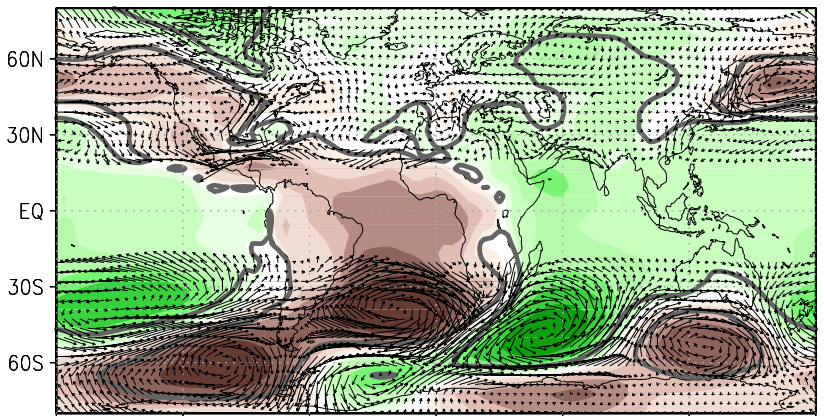

(f) Change (future-present) Eq. Mode impact mslp

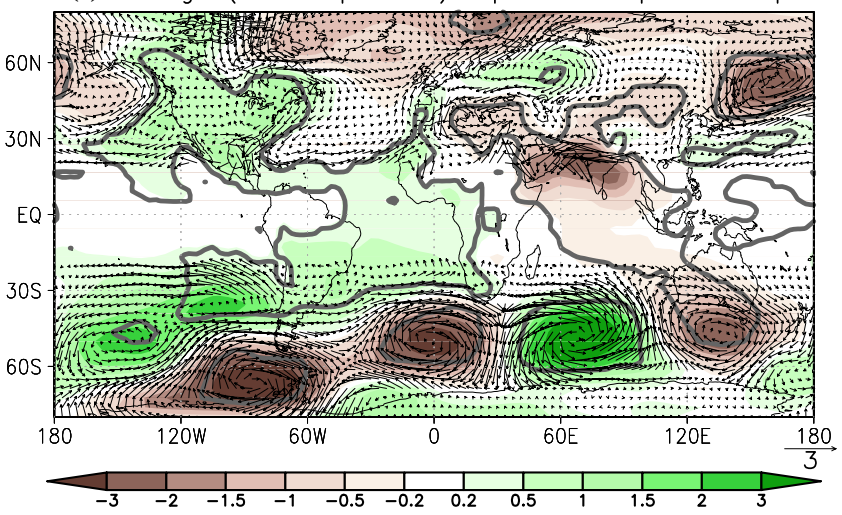

$($ alpha $=0.05)$. Hatching in (a) and (b) mark the regions where climatological SSTs are above $28{ }^{\circ} \mathrm{C}$. Arrows in (a, b, d, e and f) show the corresponding impact on surface winds $\left(\mathrm{ms}^{-1}\right)$ poleward of $20^{\circ}$. In plots (a) and (b) the winds are shown only over the regions where the impact of the Equatorial Mode on land surface temperature is statistically significant $($ alpha $=0.05)$

responsible for the local maximum of low level climatological convergence (Fig. 4d), which is also related to a maximum of climatological precipitation there (not shown). Conversely, in the future SSTs such maximum disappears (Fig. 6b), and so does the local maximum of climatological low level convergence (Fig. 4e) and precipitation (not shown). That is, due to changes in the climatological SSTs, in the future simulations the main centers of climatological divergence and precipitation in the Indian basin are shifted to the west. Because the impact of any remote source of 
(a) Present SST

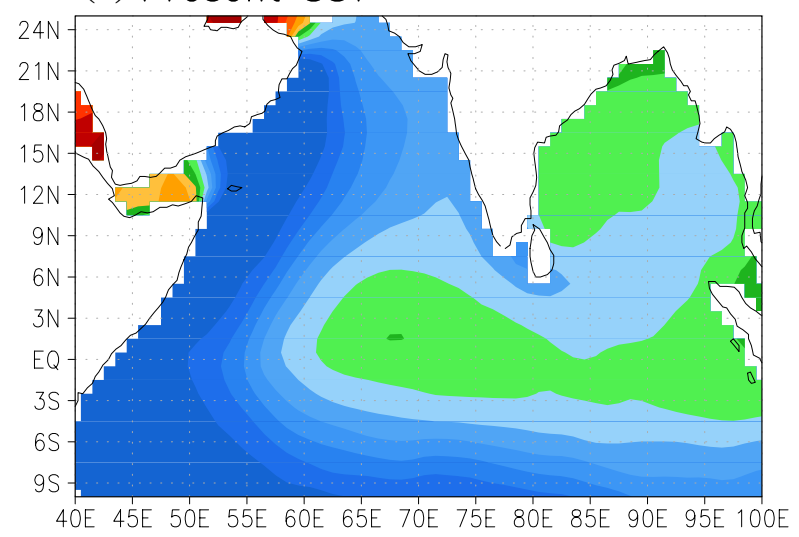

(b) Future SST

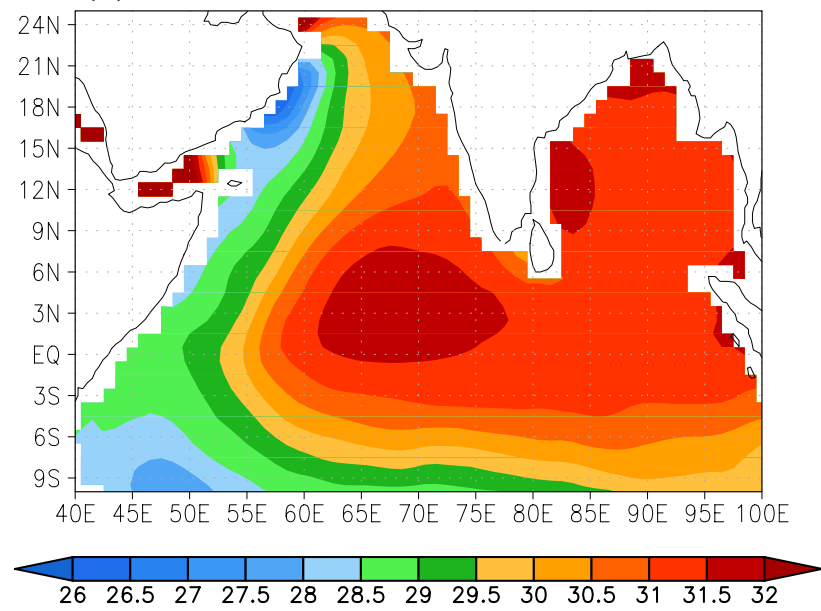

Fig. 6 Averaged climatological SST $\left({ }^{\circ} \mathrm{C}\right)$ for summer (July to September) in the present 1971-2000 (a) and future 2071-2100 (b)

anomalous divergence would be directed to the regions with maximum climatological divergences, the main subsidence over the Indian Ocean related to the Atlantic Equatorial Mode in the future climate is shifted to the west of the basin and the observed link between the Indian Monsoon and the Equatorial Atlantic mode will be weakened.

\subsection{Extratropics}

In response to the Equatorial Mode, the model simulates rainfall increases over the continental areas surrounding the North Atlantic basin centered around $40^{\circ} \mathrm{N}$ (Fig. 3a). In particular, there are significant increases in the present climate over the eastern North America, and over Western Europe, above the north coast of the Mediterranean Sea, in correspondence with Losada et al. (2012). The positive phase of the Equatorial Mode also enhances rainfall over the South Atlantic, in a wide area centered around $35^{\circ} \mathrm{S}$ and $10^{\circ} \mathrm{W}$ in the present climate. These South Atlantic rainfall anomalies shift approximately $10^{\circ}$ to the east in a warmer climate (Fig. 3b). Such shift could be connected to the eastward shift of the maximum local rainfall anomalies over the Tropical Atlantic Ocean that were discussed previously. In the following, we show that this eastward shift in positive rainfall anomalies (and related divergence) over the equatorial Atlantic has consequences for the teleconnections of the Equatorial Mode to the extratropics.

In addition to rainfall anomalies, the Atlantic Equatorial Mode impacts extratropical continental surface temperatures. In Fig. 5a we show the anomalous surface temperatures associated with a positive Atlantic Equatorial Mode event in the present climate. There are regions of increased surface temperature, like the Western North America, Central southern Europe, South Africa and a broad region that spans from Iran to Kazakhstan, and also regions of negative anomalies, like central Canada to the south of the Hudson Bay, Mongolia and Southern East Russia and the western Australia. The advection of mean temperatures by the anomalous meridional wind can explain most of these surface anomalies (Fig. 5a). These extratropical anomalous winds are, in turn, related to the anomalous sea level pressure (Fig. 5d), which shows a correspondence with anomalies of geopotential height at high levels (Fig. 7a), suggesting an extratropical barotropic response to the Atlantic Equatorial Mode. This could be related to stationary Rossby waves, as proposed by García-Serrano et al. (2011), who noted that Rossby waves could propagate to central Europe in response to the mature phase of the Atlantic Equatorial Mode.

To further study the extratropical teleconnections due to stationary Rossby Waves we show in Fig. 7b the stationary total wave number $\left(K_{s}\right)$ calculated from the climatological zonal wind at $200 \mathrm{hPa}$ as:

$K_{s}=\sqrt{\frac{\beta_{M} R_{t}}{\bar{v}}}$

where $\beta_{M}$ is cos (latitude) times the meridional gradient of the absolute vorticy on the sphere, $R_{t}$ is the Earth's radius and $\bar{v}$ is the climatological mean of the relative rotational rate of the atmosphere (Hoskins and Karoly 1981; Hoskins and Ambrizzi 1993). Rossby waves can propagate provided their zonal wavenumber is smaller or equal to $K_{s}$ and local maxima of $K_{s}$ provides Rossby waveguides. In the Southern Hemisphere there are two clear waveguides centered around $30^{\circ} \mathrm{S}$ and $50^{\circ} \mathrm{S}$, consistent with findings of Ambrizzi et al. (1995) for the boreal summer atmosphere. The anomalous cyclones and anticyclones found in the Southern Hemisphere are thus consistent with stationary Rossby waves trapped into these two waveguides. In the North Hemisphere there is also a waveguide related to the North Atlantic jet and to the North African-Asian jet with a total wavenumber of approximately five, which is consistent with the apparent wavenumber-5 structure in Fig. $7 \mathrm{a}$. 


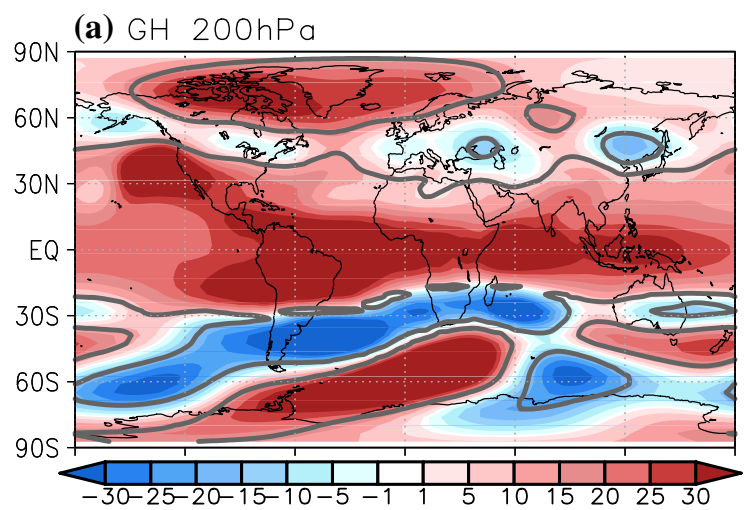

(b) $\mathrm{Ks} 200 \mathrm{hPa}$

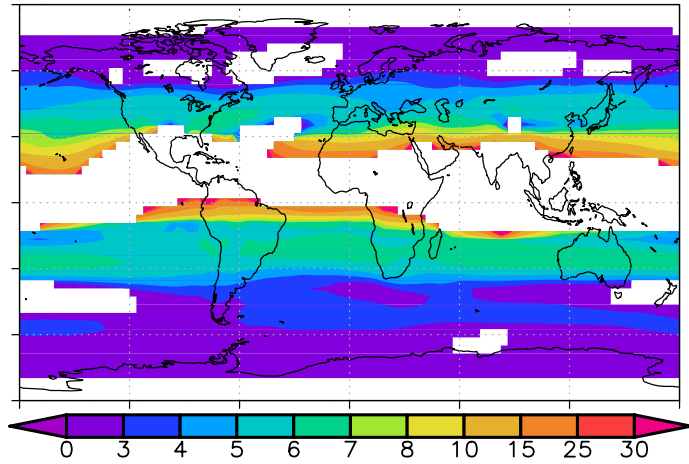

(c) Div. $100-300 \mathrm{hPa}$

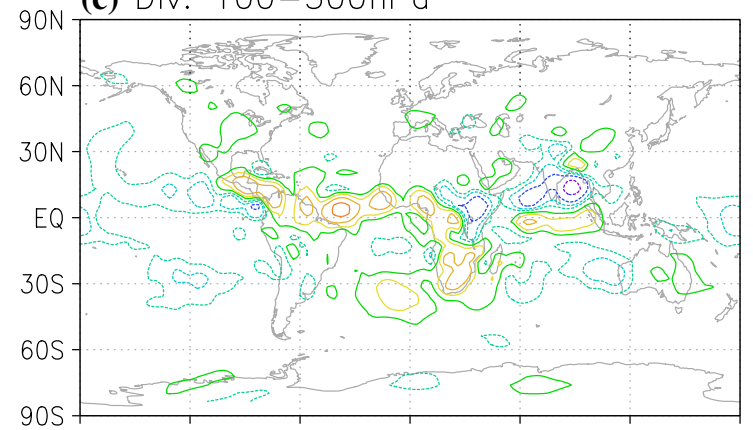

(d) RWS total 100-300hPa

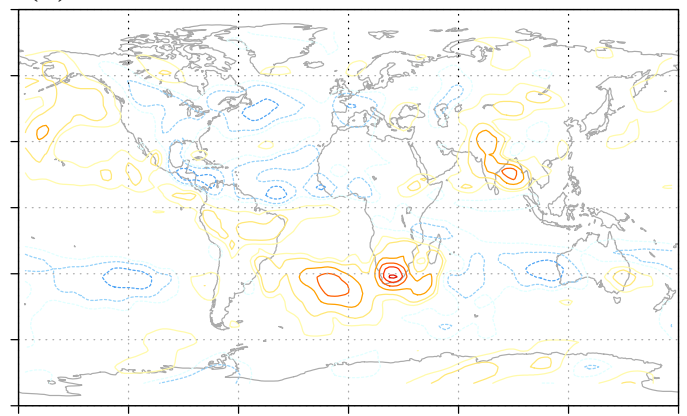

(e) 1 st resp. term $100-300 \mathrm{hPa}$

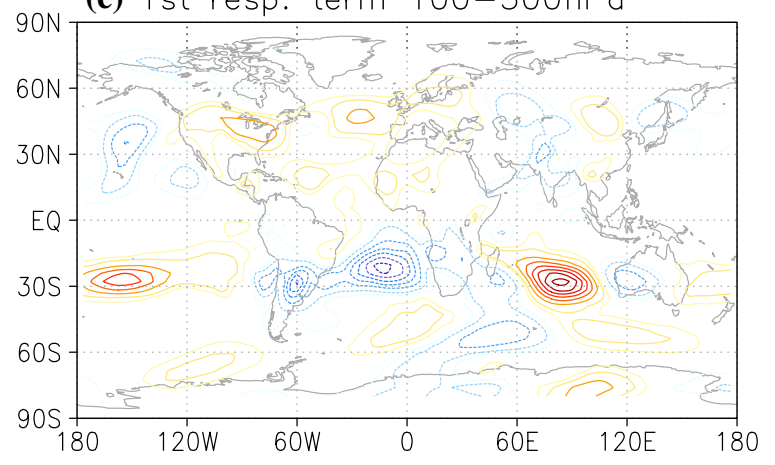

(f) 2nd resp. term 100-300hPa

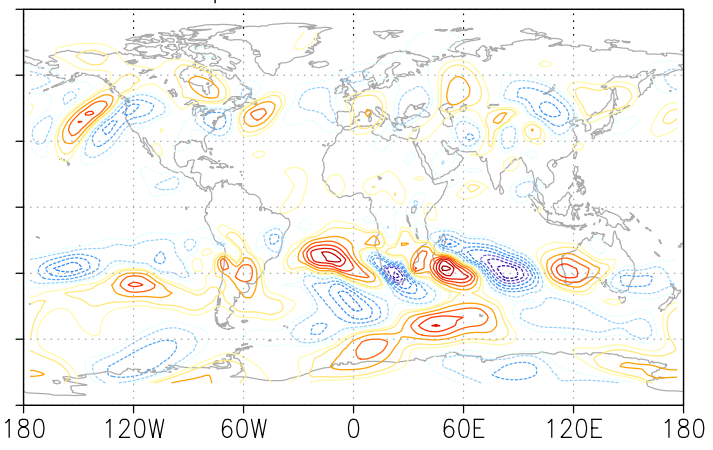

Fig. 7 In the present climate: a Impact of the Equatorial Mode on summer (July to September) geopotential height (m) at $200 \mathrm{hPa}$. Statistically significant regions (alpha $=0.05$ ) are marked by a thick gray contour. b Summer stationary total wave number $\left(K_{s}\right.$, adimensional) at $200 \mathrm{hPa}$. c Impact of the mode on summer divergence averaged between 100 and $300 \mathrm{hPa}$. Contour levels are marked

To look for the sources of these Rossby waves the anomalous rossby wave sources (RWS) have been calculated using Eq. (6) in the appendix and are shown in Fig. 7d. Following Rodwell and Jung (2008) we have chosen to integrate vertically the Rossby wave sources between 300 and $100 \mathrm{hPa}$ to avoid biasing the diagnostic due to changes in the level of convective outflow in the tropics. In our case, the second term in Eq. (6), related to the anomalous divergence, dominates the anomalous Rossby wave sources. This can be seen when comparing the anomalous Rossby wave sources in Fig. 7d with the anomalous divergence in at $\pm 0.2, \pm 0.5, \pm 1, \pm 2$ and $\pm 3\left(10^{-6} \mathrm{~s}^{-1}\right) \mathbf{d}$ Anomalous RWS $\left(10^{-11} \mathrm{~s}^{-2}\right)$, e first $\left(-\overrightarrow{v_{\psi}}, \nabla \bar{\xi}\right)$ and $\mathbf{f}$ second $\left(-\overrightarrow{v_{\psi}} \nabla \xi^{\prime}\right)$ response terms $\left(10^{-11} \mathrm{~s}^{-2}\right)$ to the anomalous RWS averaged over 100-300 $\mathrm{hPa}$ pressure levels. (See details in the text). For (d, e and $\mathbf{f}$ ) contour intervals are marked at $\pm 1, \pm 2, \pm 4, \pm 6, \pm 8, \pm 10, \pm 12$ and \pm 14 . Negative values are marked with dashed lines

those same levels (Fig. 7c). There is a clear correspondence between the main anomalies of divergence and the total anomalous RWS. In addition to the tropical sources, there are extratropical Rossby wave sources (Fig. 7d). The most notable of them is the positive source located in the south Atlantic, with a center in approximately $40^{\circ} \mathrm{S}, 10^{\circ} \mathrm{W}$. The anomalous divergence associated with this RWS could be related to negative divergence anomalies at approximately $15^{\circ} \mathrm{S}$ through a meridional overturning circulation (Fig. 7c); the anomalous convergence in $15^{\circ} \mathrm{S}$, in turn, would be related to the main tropical divergence at roughly 
$10^{\circ} \mathrm{N}$ through a Hadley-type anomalous cell. This extratropical RWS is responsible for much of the Rossby wave response seen in the South Atlantic and Indian Oceans (Figs. 5d, 7a), which is more clearly seen when looking at the stationary response to the RWS.

To analyze the stationary response to the RWS we show in Fig. 7e, f the last two terms in Eq. (7) in the appendix, which represent the advection of mean vorticity by the anomalous rotational wind and the advection of anomalous vorticity by the mean rotational wind, respectively. In both of them, the propagation of Rossby waves at three different latitudes can be clearly seen: one in the northern Hemisphere, between $30^{\circ}$ and $60^{\circ} \mathrm{N}$, and two in the Southern Hemisphere, centered at $30^{\circ} \mathrm{S}$ and $50^{\circ} \mathrm{S}$, respectively. These correspond very well to the waveguides highlighted in Fig. $7 \mathrm{~b}$ that were previously commented. There is a nice correspondence between both response terms in the south Indian Ocean over the most southern waveguide, where the RWS is very small (Fig. 7d-f). This model response can, thus, be understood as a Rossby wave being forced by the anomalous RWS in the South Atlantic, which is related to the local anomalous divergence (Fig. 7c, d). Such anomalous RWS is also in part responsible for the Rossby waves propagating at $30^{\circ} \mathrm{S}$, though the RWS at other locations in this waveguide seem to be also contribution to them. In particular, the ones related to anomalous divergence at upper levels over South Africa, and to anomalous convergence over the south Indian Ocean off coast of Australia and over the South Pacific. In the Northern Hemisphere the response terms in Fig. 7e, f seem to be excited by different RWS, as the ones over south France, the Caspian sea, North America below the great Lakes and over the North Atlantic offshore of the Gulf of St. Lawrence, which are all related to anomalous upper level divergence (Fig. 7c) and statistically significant positive rainfall anomalies (Fig. 3a). These extratropical RWS are ultimately forced by the tropical forcing.

There is also a correspondence between the response terms in Fig. 7e, $\mathrm{f}$ and the geopotential anomalies in upper levels in Fig. 7a. The anomalous rotational winds related to an anomalous low are directed southward to the west of the low and northward to the east in the Northern Hemisphere. Taking into account the poleward gradient of absolute mean vorticity and the negative sign in the definition of the second term in Eq. (7) in the appendix, the centers of the extratropical anomalous lows in the geopotential height are expected to be located over the regions where there is a zonal change between positive and negative values of this second term in Eq. (7) in the appendix (advection of mean vorticity by the anomalous rotational wind) in the Northern Hemisphere, and the reverse in the Southern Hemisphere, which can be seen when comparing Fig. 7a, e.

Regarding the future climate, the analysis of the stationary total wave number $K_{s}$ (Fig. 8 b) reveals that the location of the waveguides in the southern and northern hemisphere does not change with respect to the present simulations. Thus, we expect that the changes in the extratropical Rossby waves in the future simulations will be due to the changes in the response to the Equatorial Mode, and not to changes in the mean flow.

As we explained in the previous section, in a warmer climate the impact of the Atlantic Equatorial Mode changes in the tropics. There is a shift to the east in the rainfall maximum anomalies in the equatorial Atlantic related to a shift in the convergence at low levels (Figs. 3, 4). At high levels the maximum in tropical divergence is also shifted to the east, and there is an increased response over West Africa (Fig. 8c). This eastward shift in the tropical divergence over the Atlantic is accompanied by a shift to the east in the pole of extratropical divergence located over the South Atlantic of approximately $10^{\circ}$ and the reduction of the divergence pole over the North Atlantic, offshore of the Gulf of St. Lawrence. The divergence at high levels over southern Europe is also shifted to the east from the south of France in the present simulations to the north of the Adriatic sea in the future ones. Over the Indian Ocean anomalous rainfall and divergence at low and high levels change in the tropics: in a warmer climate the impact of the Atlantic Equatorial Mode in rainfall is shifted to the west of the Indian basin and it is greatly reduced (Fig. 3). Consistently, the extratropical divergence at high levels is also reduced over the South Indian Ocean and over the Asian continent (Fig. 8c).

These changes in the divergent field have their implication in the RWS (Fig. 8d): the main RWS in the South Atlantic is displaced eastwards to the Greenwich meridian in the future simulation. This, in turn, displaces to the east the other Rossby wave sources in the southern Hemisphere, like the one in the eastern South Pacific. Some of the poles of RWS in the Northern Hemisphere are also shifted to the east, as the ones over the North Atlantic and over South Europe. The former one is also weakened in a future climate in correspondence with a weaker divergence at high levels (Fig. 8c). In addition, most of the RWS over Asia are weakened.

These changes in the location and strength of the RWS modify the location and strength of the response and, thus, of the extratropical geopotential height anomalies (Fig. 8a, e, f). The displacement to the east of the stationary Rossby waves in the southern Hemisphere is also seen in the mean sea level pressure (Fig. 5e). In agreement with the displacement of the Rossby wave response over Australia (Figs. 7e, f, 8e, f), the negative anomaly in geopotential height at $200 \mathrm{hPa}$ located over east Australia in the present simulation is displaced to the dateline in the future simulation (Figs. 7a, 8a). This structure is barotropic and advects cold surface mean temperatures through the anomalous wind in the present simulation (Fig. 5a). The 
(a) $\mathrm{GH} 200 \mathrm{hPa}$

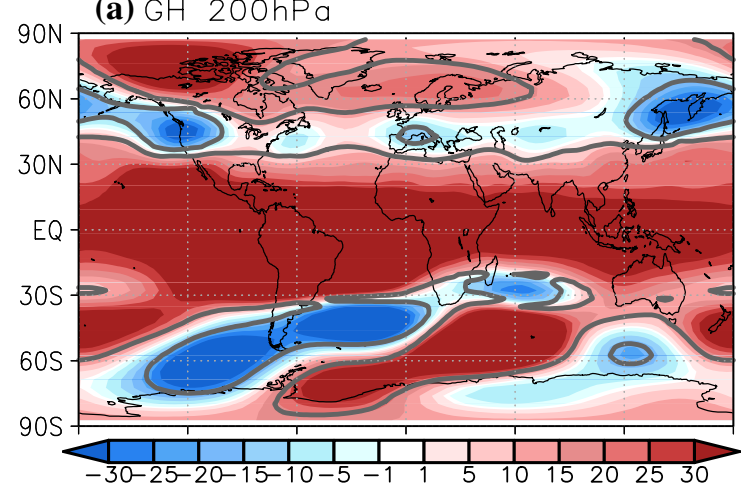

(c) Div. $100-300 \mathrm{hPa}$

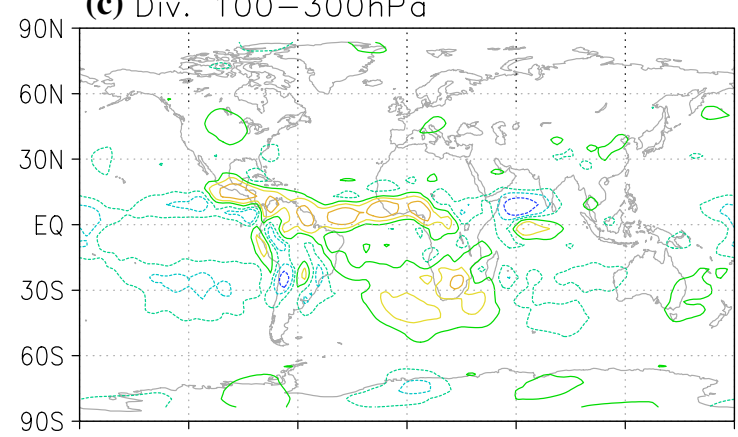

(e) $1 \mathrm{st}$ resp. term $100-300 \mathrm{hPa}$

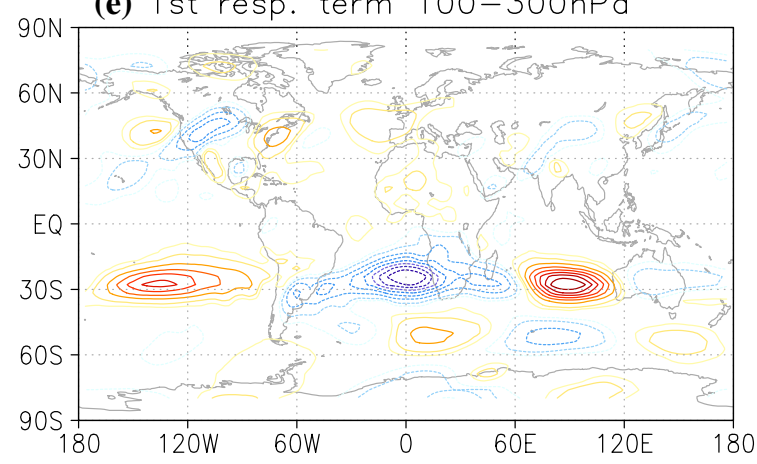

(b) $\mathrm{Ks} 200 \mathrm{hPa}$

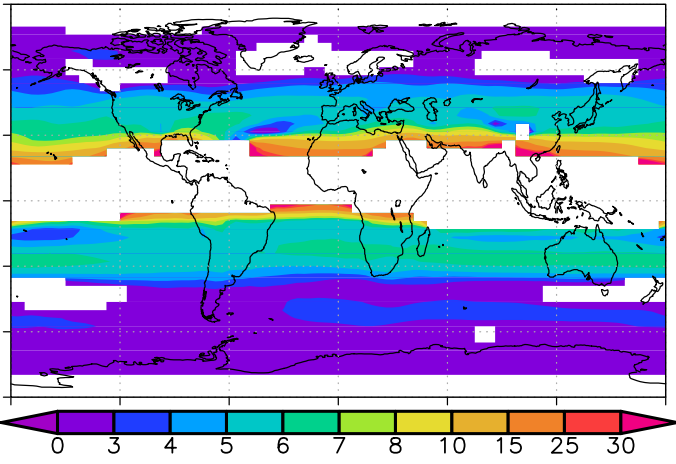

(d) RWS total $100-300 \mathrm{hPa}$

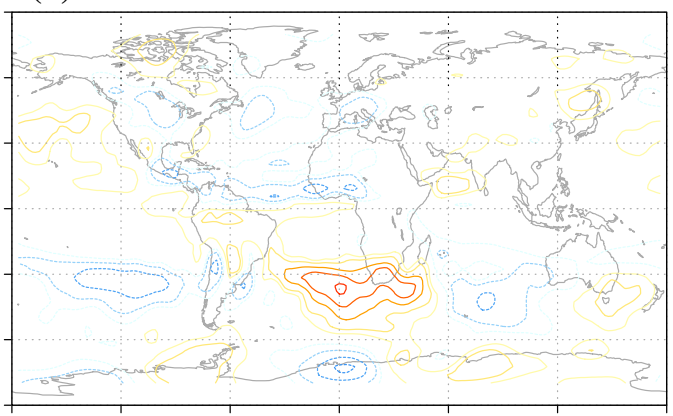

(f) 2nd resp. term $100-300 \mathrm{hPa}$

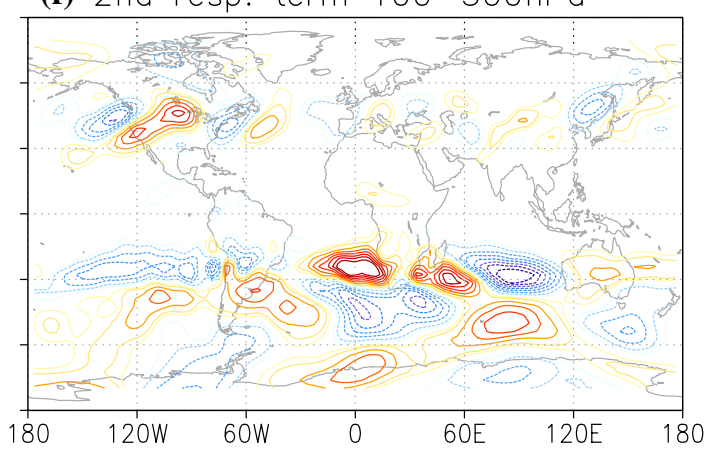

Fig. 8 Same as Fig. 7 but for the future climate

eastward shift in the future simulation reduces meridional wind anomalies and, thus, surface temperature anomalies. For this reason, over Australia the impact of the Atlantic Equatorial Mode on surface temperatures significantly changes in the future (Fig. 5b). Following the shift of the local RWS over Southwestern Europe, the eastward shift of the cyclonic barotropic anomaly from the present to the future simulation also implies a change in surface anomalous winds over the western Mediterranean from southerly in the present climate (Fig. 5a) to northerly in the future climate (Fig. 5b). This, in turn, changes anomalous surface temperatures over Western Europe from warm anomalies in the present simulation to cold ones in the future simulation. Over North America, the eastward shift and weakening of the barotropic cyclonic anomaly located over the Labrador Peninsula (Figs. 7a, 8a, 5d, e) weakens the anomalous northerly winds at the surface over the Great Lakes and thus the cold surface temperature anomalies in the future simulation (Fig. 5a, b). The weakening of the RWS over Asia (Fig. 8d) is translated into a weakening of the Rossby wave response in the region (Fig. 8e) and, thus, of the anomalies in geopotential height (Figs. 8a, 5e). At the surface, the northerly surface wind anomalies associated with the barotropic cyclone located over the Caspian sea in the present simulation are weakened in the future one (Fig. 5f) and so is the temperature surface anomaly (Fig. 5b).

In summary, the eastward shift in the Tropical Atlantic divergence and the weakening of the convergence over 
Table 3 Set of additional simulations performed (first column), name of the experiments (second column), climatological (third column) and anomalous (fourth column) SSTs used as boundary conditions,

\begin{tabular}{|c|c|c|c|c|c|}
\hline Set & Name & Climatological SSTs & SST anomalies & $\mathrm{CO}_{2}$ concentration & Sea Ice concentration \\
\hline \multirow[t]{3}{*}{ FutuSIC } & FutuSIC_clim & $1971-2000$ & No & Present & 2071-2100 RCP85 \\
\hline & FutuSIC_pos & $1971-2000$ & ATL mode + & Present & 2071-2100 RCP85 \\
\hline & FutuSIC_neg & $1971-2000$ & ATL mode- & Present & 2071-2100 RCP85 \\
\hline \multirow[t]{3}{*}{ FutuCo2 } & FutuCo2_clim & $1971-2000$ & No & $2.9 *$ present & $1971-2000$ \\
\hline & FutuCo2_pos & $1971-2000$ & ATL mode + & $2.9 *$ present & $1971-2000$ \\
\hline & FutuCo2_neg & $1971-2000$ & ATL mode- & $2.9 *$ present & $1971-2000$ \\
\hline \multirow[t]{3}{*}{ FutuSST } & FutuSST_clim & 2071-2100 RCP85 & No & Present & $1971-2000$ \\
\hline & FutuSST_pos & 2071-2100 RCP85 & ATL mode + & Present & $1971-2000$ \\
\hline & FutuSST_neg & 2071-2100 RCP85 & ATL mode- & Present & $1971-2000$ \\
\hline \multirow[t]{3}{*}{ FutuGrads } & FutuGrads_clim & 2071-2100 RCP85 - $2.8^{\circ} \mathrm{C}$ & No & Present & $1971-2000$ \\
\hline & FutuGrads_pos & 2071-2100 RCP85 - $2.8^{\circ} \mathrm{C}$ & ATL mode + & Present & $1971-2000$ \\
\hline & FutuGrads_neg & 2071-2100 RCP85 - $2.8^{\circ} \mathrm{C}$ & ATL mode- & Present & $1971-2000$ \\
\hline \multirow[t]{3}{*}{ FutuTemp } & FutuTemp_clim & $1971-2000+2.8^{\circ} \mathrm{C}$ & No & Present & $1971-2000$ \\
\hline & FutuTemp_pos & $1971-2000+2.8^{\circ} \mathrm{C}$ & ATL mode+ & Present & $1971-2000$ \\
\hline & FutuTemp_neg & $1971-2000+2.8^{\circ} \mathrm{C}$ & ATL mode- & Present & $1971-2000$ \\
\hline
\end{tabular}

reference $\mathrm{CO}_{2}$ concentration (fifth column) and sea ice concentration used as boundary conditions (sixth column) for the experiment the tropical Indian Ocean in the future simulation with respect to the present one lead to an eastward shift of the divergence over the extratropical Atlantic and a weakening of the divergent anomalies over the Indian Ocean, respectively. These changes are connected through the RWS to the strength and location of the stationary Rossby Wave response which marks the location of anomalies in geopotential height in the extratropics. These extratropical geopotential height anomalies can, in turn, explain the surface temperature anomalies in the extratropics through the anomalous advection of mean surface temperature. In this way, in a future climate the Atlantic Equatorial Mode changes the impact in surface temperatures over regions like Southwestern Europe, East Australia, Asia or North America. Previous works have posed that the tropical diabatic heating in the Tropical Atlantic (that could be, in turn, produced by anomalous SSTs associated to the Equatorial Mode) is related to temperature conditions and summer heat waves in western Europe, through the excitation of extratropical Rossby waves (Cassou et al. 2005; DellaMarta et al. 2007). Our results imply a possible change in the Rossby wave response to an equal warming in the Tropical Atlantic, and thus a change of the impact in the European heat waves in summer.

\subsection{Origin of the changes}

Up to now we have analyzed the changes in the impact of the Atlantic Equatorial Mode in a future warmer climate. We have fixed the mode and we have changed the climatological SSTs, sea ice concentration and $\mathrm{CO}_{2}$ concentration in the simulations. In this section we want to draw light into the origin of the changes in the impacts. For this sake we have performed additional simulations changing the prescribed $\mathrm{CO}_{2}$ concentration (FutuCO2 simulations), the climatological sea ice concentration (futuSIC simulations) or the SST fields (futuSST simulations), leaving the other two factors as in the present climate. As for the future and present simulations, each set of simulations is composed by three simulations (positive and negative phase of the Equatorial Mode and climatology). A description of this new sets is displayed in Table 3.

In Fig. 9 we show the comparison between each additional set of simulations and the present ones by means of the changes in the impact of the Equatorial Mode. The change of sea ice concentration to future conditions does not alter significantly the impact of the Atlantic Equatorial Mode in rainfall (Fig. 9a). It influences the response of surface temperatures in some extratropical locations as northwestern Russia (Fig. 9f) by modifying the position of mean sea level pressure anomalies in the Northern Hemisphere (not shown). However, these anomalies do not agree with the ones obtained when comparing the future simulations with the present ones (Fig. 5c).

Though altering only $\mathrm{CO}_{2}$ concentration cannot account for the full response of future simulations, it has a clear impact on tropical rainfall (Fig. 9b). It can explain the increase of rainfall related to the Equatorial Mode over northern South America and contributes to rainfall changes over the equatorial Atlantic, western equatorial Africa and South Asia and eastern Indian Ocean. Conversely, the changes in surface temperature related to the modification of $\mathrm{CO}_{2}$ are weak (Fig. $9 \mathrm{~g}$ ). 
The changes with respect to the present simulations obtained with futuSST are very similar to the ones obtained in the future simulation (Fig. 9c, h). This suggests that it is the change in climatological SSTs which matter the most for the changes in the impacts of the Equatorial Mode on rainfall and surface temperatures that we have highlighted in the previous sections. The change in climatological SSTs show a world wide increase of temperatures (Fig. 1b). The average $\left(70^{\circ} \mathrm{S}\right.$ to $\left.70^{\circ} \mathrm{N}\right)$ difference in SST from the present to the future CMIP5 simulations is $2.8^{\circ} \mathrm{C}$. However, some regions warm more than others. For instance, the tropical oceans, notably the eastern Pacific, eastern Atlantic and western Indian Oceans warm further than the surrounding areas. In particular, the westward enhancement of climatological SSTs over the tropical Indian Ocean (Figs. 1b, 6) could be responsible for the change in climatological divergence at low levels in this basin (Fig. 4c, d), which, in turn, seems to be the reason for the change in the impact of the Atlantic Equatorial Mode in this basin (Fig. 3). Chiang and Lintner (2005) argue that more important than the overall anomaly in SST is its gradient for establishing the tropical rainfall anomalies. To evaluate if the main changes in the impact of the Equatorial Mode are related to the overall warming or to the change in local SST gradients (due to the uneven tropical warming, Fig. 1b) we have performed two sets of simulations, FutuGrads and FutuTemp. In the first set, FutuGrads, we have changed the SST climatological field to the future one (2071-2100, using RCP85 scenario) minus $2.8{ }^{\circ} \mathrm{C}$ at each grid point. In this way, we retain the future SST gradients but reduce the average SST to the present conditions. In the second set, FutuTemp, we have added $2.8^{\circ} \mathrm{C}$ to each grid point in the present climatological SST field. In this way, we retain the future average increase in SSTs but leaving SST gradients as in the present simulations (see Table 3 for more details).

The difference between the impacts of the Equatorial Mode in FutuGrads set of simulations and the present one is weak (Fig. 9d, i). Its main effect is to contribute to the modification of rainfall anomalies over the Indian Ocean, thus confirming the results shown in Sect. 3.1. Conversely, the results from FutuTemp set of simulations (Fig. 9e, j) are very similar to the ones obtained with the SST future climatology (Fig. 9c, h) and also to the future set (Figs. 3c, $5 \mathrm{c})$. This is, most of the change in the impact of the Equatorial Mode from present to future conditions that was highlighted in the previous section can be explained by the average increase of $2.8{ }^{\circ} \mathrm{C}$ in SST climatology. This result diverges from the one obtained by Chung et al. (2014) regarding the changes of the Pacific El Niño impacts from the present to a future climate. They showed that, unlike our case, the patterns of the precipitation response were more strongly influenced by the spatial structure of the change in SST climatologies.
However, in our experiments it is the mean increase in climatological SSTs that drives eastward the main rainfall increase associated with the Equatorial Mode over the Tropical Atlantic, which, in turn, modifies the location of the divergence at high levels over the Atlantic and, thus, the Rossby Wave sources (not shown). These, in turn, shift eastward the location of extratropical pressure anomalies and, thus, modify surface temperature anomalies through the anomalous advection of climatological temperatures (not shown).

\section{Summary and conclusions}

We have analyzed the local and remote impacts of the Equatorial Mode under present and future climate conditions. We followed an AGCM-based approach in which the prescribed SSTs were calculated as a superposition of the same anomalous pattern associated to the Equatorial Mode upon two different climatologies, representative of the present and future climates, respectively. The SST anomalous pattern is consistent with the Atlantic Equatorial Mode pattern observed during the period 1971-2000. The present climatological SSTs correspond to the observed SSTs averaged over the 1971-2000 period. For the future climate, the SSTs were calculated as the present climatological SSTs plus the changes in SSTs simulated by 11 models from the CMIP5 experiment (Table 2). With this approach we try to avoid errors derived from the strong SST biases present in current GCMs, especially over the Tropical Atlantic Ocean. For consistency reasons, the sea ice concentration and the absorption coefficient in the $\mathrm{CO}_{2}$ band were changed accordingly in the future climate simulations.

Our results show that the impact of the Equatorial Mode will change under future climate conditions in both the tropics and the extratropics. The changes will be necessarily linked to changes in the climatological SST, sea ice concentration or $\mathrm{CO}_{2}$ absorption coefficient, as they are the only three factors that vary between present and future simulations.

In the tropics, the main centers of anomalous divergence located over the Tropical Atlantic in response to the Equatorial Mode will be shifted northeasterly. Over the Indian Ocean, the impact of the Atlantic Equatorial Mode over the Indian Monsoon precipitation will be weakened. We show that the former is linked to the increase in the climatological SST over the Tropical Atlantic: In the future simulations the convection threshold of $28^{\circ} \mathrm{C}$ is reached over the whole Tropical Atlantic basin, north of the equator and up to $15^{\circ} \mathrm{N}$, approximately. Such future climatology allows tropical convection to take place over a wider area than in the present climate. In turn, the change in the response of the Indian Monsoon to the Equatorial Mode is linked to changes in the location of the low level climatological 
(a) Precip. FutuSIC-present

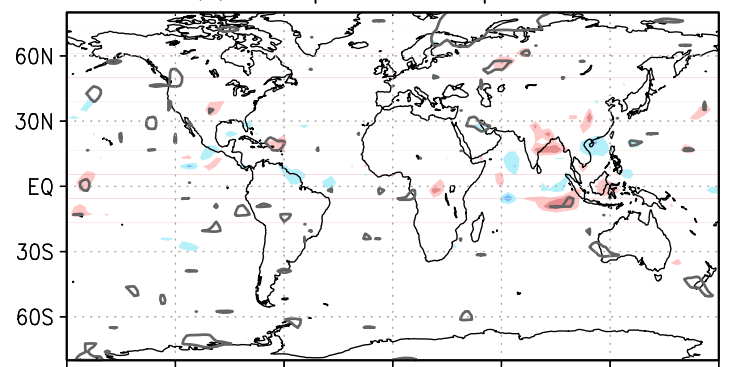

(b) Precip. FutuCO2-present

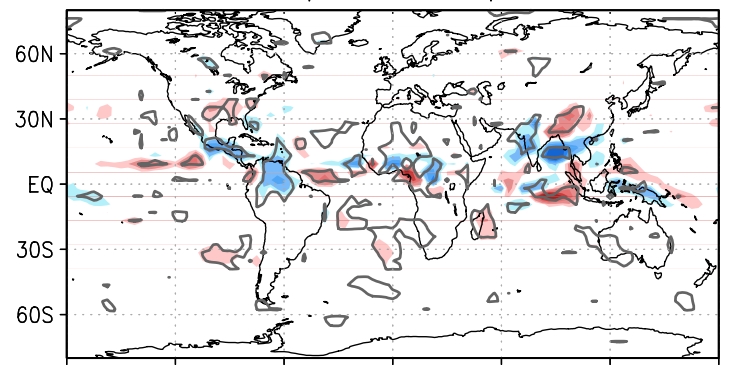

(c) Precip. FutuSST-present

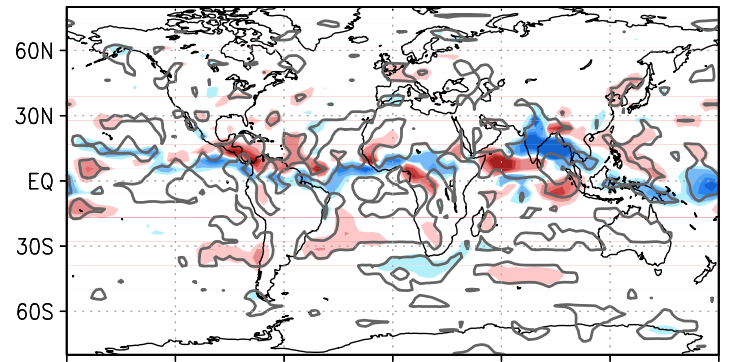

(d) Precip. Futugrads-present

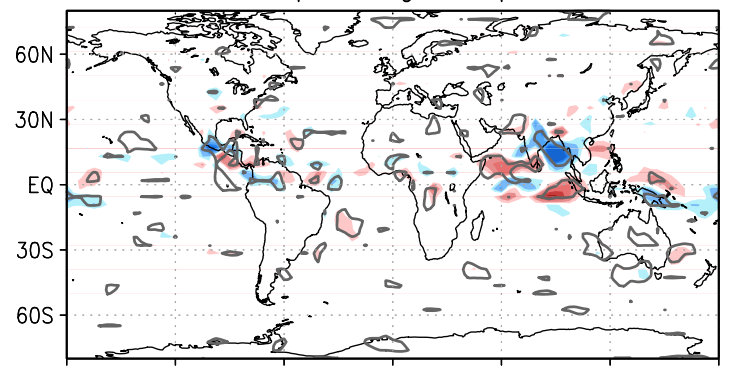

(e) Precip. Fututemp-present

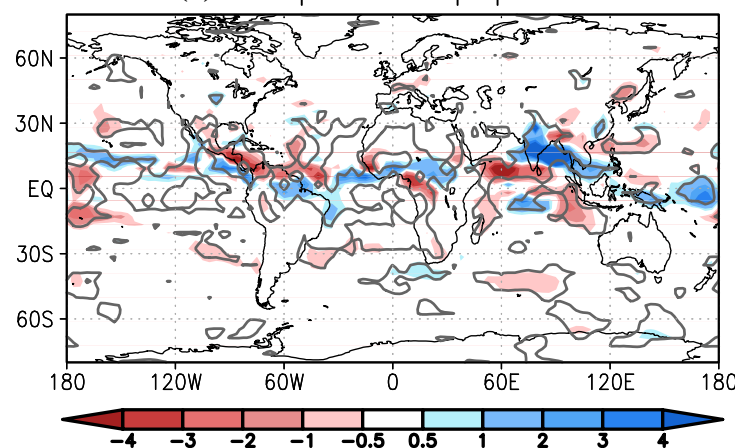

convergence and precipitation in the Bay of Bengal. We have shown that such changes can also be related to changes in the climatological SSTs over the Indian Ocean.

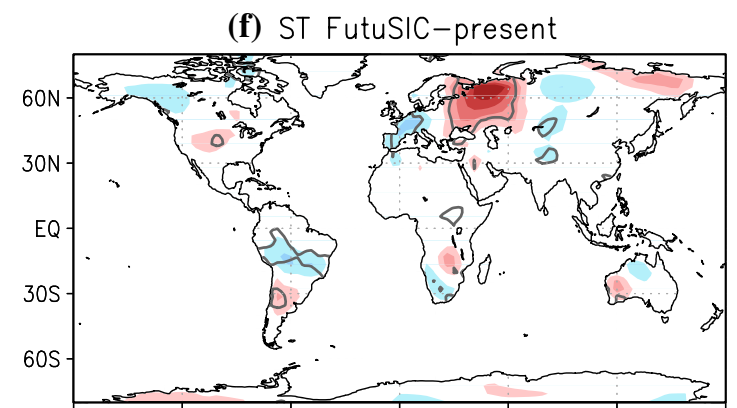

(g) ST FutuCO2-present

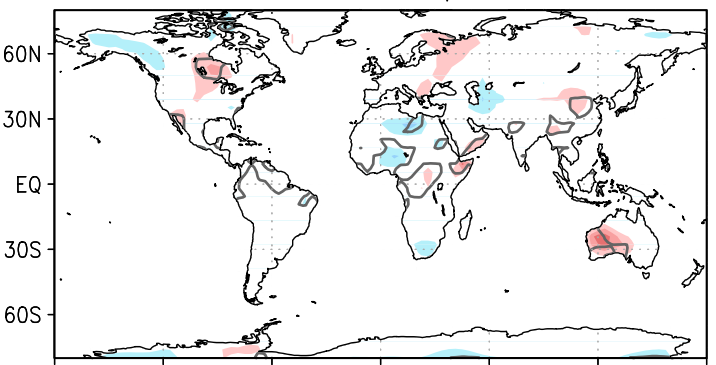

(h) ST FutuSST-present

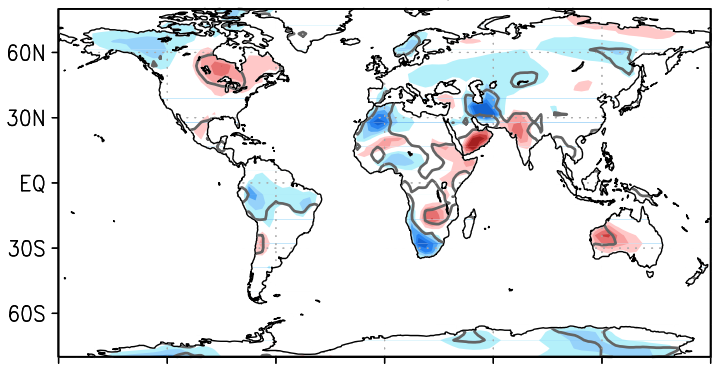

(i) ST Futugrads-present

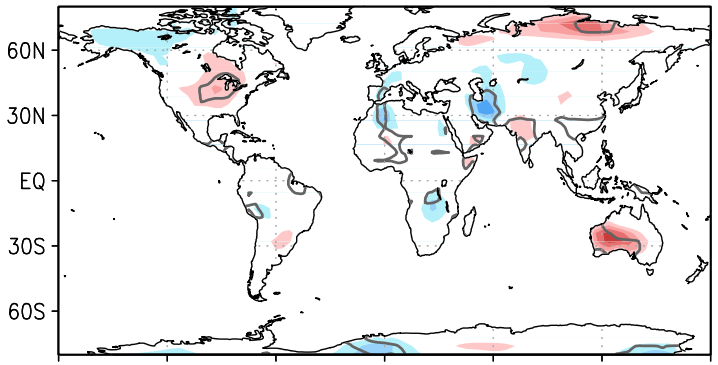

(j) ST Fututemp-present

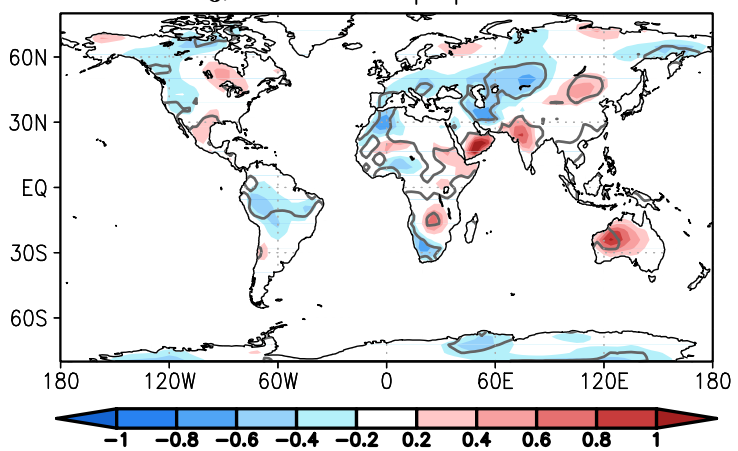

In the extratropics, the anomalous response to the Equatorial Mode in both present and future climates has the form of extratropical Rossby waves that project onto surface 
4 Fig. 9 Changes in the impact of the Equatorial Mode in rainfall $\left(\mathrm{mm} /\right.$ day) (left column) and land surface temperatures $\left({ }^{\circ} \mathrm{C}\right.$, right column) between the simulations FutuSIC (first row), FutuCO2 (second row), FutuSST (third row), Futugrads (fourth row), Fututemp (fifth row) and the present simulations. Statistically significant regions $($ alpha $=0.05)$ are marked by a thick gray contour. Changes are calculated as the differences between the impact of the Equatorial mode (defined as the positive minus negative simulations) in each set (FutuSIC, FutuCO2, FutuSST, Futugrads and Fututemp, see Table 3) minus the impact in the present set (Table 1)

temperature anomalies due to the anomalous advection of climatological surface temperature. However, the main centers of those waves appear shifted to the east in the future climate with respect to the present one, which, in turn, produces a change in the extratropical surface temperature response to the Equatorial Mode. We show that such a shift simulated by the AGCM is mainly related to the eastward shift of the anomalous divergence in the Tropical Atlantic.

We have also analyzed the contribution of climatological SSTs, sea ice concentration and $\mathrm{CO}_{2}$ to the changes in the impact of the Equatorial Mode described above. We have shown that the change in sea ice concentration is the least important factor in the AGCM response, while the direct change in $\mathrm{CO}_{2}$ produces a bigger impact, especially on tropical precipitation. However, the dominant factor are climatological SSTs. Regarding the latter, we have investigated separately the role of the world-wide mean SST increase and the change in the SST spatial structure from the present to the future climate. Our results show that, although the changes in the SST spatial structure and concentration of $\mathrm{CO}_{2}$ have a non-negligible impact in the response over the Indian sector, the key factor controlling the changes in the AGCM response to the Equatorial Mode is the spatial averaged increase of $2.8^{\circ} \mathrm{C}$ in climatological SSTs.

Acknowledgments The research leading to these results has received funding from the European Union Seventh Framework Programme (FP7/2007-2013) under grant agreement $\mathrm{n}^{\circ}$ 603521. This work was also supported by the Spanish project CGL2012-38923-C02-01. We acknowledge the World Climate Research Programme's Working Group on Coupled Modelling, which is responsible for CMIP, and we thank the climate modeling groups (listed in Table 2 of this paper) for producing and making available their model output. For CMIP the U.S. Department of Energy's Program for Climate Model Diagnosis and Intercomparison provides coordinating support and led development of software infrastructure in partnership with the Global Organization for Earth System Science Portals.Open Access This article is distributed under the terms of the Creative Commons Attribution License which permits any use, distribution, and reproduction in any medium, provided the original author(s) and the source are credited.

\section{Appendix}

To analyze Rossby wave sources (RWS) and their stationary response we start with the vertical vorticity equation. Following Rodwell and Jung (2008) we use the shallow-atmosphere approximation and neglect the terms related to vertical advection, tilting and friction. In this case, the vertical vorticity equation reads:

$\frac{\partial \xi}{\partial t}+\nabla \cdot(\vec{v} \xi)=0$

where $\xi$ is the vertical component of the absolute vorticity, $t$ is the time and $\vec{v}$ is the horizontal wind. If we separate the wind into its divergent and rotational components $\left(\vec{v}=\vec{v}_{\chi}+\vec{v}_{\psi}\right.$, where $\vec{v}_{\chi}=\nabla \chi$ is the divergent wind and $\vec{v}_{\psi}=\vec{k} \times \nabla \psi$ is the rotational wind, $\chi$ is the velocity potential, $\psi$ the streamfunction and $\vec{k}$ the local unit vertical vector), Eq. (2) can be written as:

$\frac{\partial \xi}{\partial t}+\nabla\left[\left(\overrightarrow{v_{\chi}}+\overrightarrow{v_{\psi}}\right) \xi\right]=0 \Rightarrow \frac{\partial \xi}{\partial t}+\nabla\left(\overrightarrow{v_{\chi}} \xi\right)+\overrightarrow{v_{\psi}} \nabla \xi=0$

If we move all the terms that are related to the divergent flow to the right-hand side of the equation and leave the ones dependent on the rotational flow in the left-hand side, the vertical vorticity equation can be expressed as:

$\frac{\partial \xi}{\partial t}+\overrightarrow{v_{\psi}} \nabla \xi=-\nabla\left(\overrightarrow{v_{\chi}} \xi\right)$

The right-hand side term of Eq. (4) is known as the RWS (Sardeshmukh and Hoskins 1988). The anomalous RWS can be calculated following Qin and Robinson (1993) as:

$R W S^{\prime}=-\left[\nabla \cdot\left(\overrightarrow{v_{\chi}} \xi\right)\right]^{\prime} \simeq-\nabla \cdot\left({\overrightarrow{v_{\chi}}}^{\prime} \xi+\overrightarrow{\overrightarrow{v_{\chi}}} \xi^{\prime}\right)$

where $\overline{()}$ and ()$^{\prime}$ are the climatological mean and anomaly, respectively. Equation (5) can be further decomposed in four terms:

$R W S^{\prime}=-{\overrightarrow{v_{\chi}}}^{\prime} \cdot \nabla \bar{\xi}-\bar{\xi} \nabla \cdot{\overrightarrow{v_{\chi}}}^{\prime}-\xi^{\prime} \nabla \cdot \overrightarrow{\overrightarrow{v_{\chi}}}-\overrightarrow{\overrightarrow{v_{\chi}}} \cdot \nabla \xi^{\prime}$

Neglecting the seasonal mean of the anomalous local tendency of vorticity, Eq. (4) can be re-formulated in terms of the anomalous RWS and their stationary response as:

$R W S^{\prime}-\left(\overrightarrow{v_{\psi}} \nabla \xi\right)^{\prime}=0 \Rightarrow R W S^{\prime}-{\overrightarrow{v_{\psi}}}^{\prime} \nabla \bar{\xi}-\overrightarrow{\overrightarrow{v_{\psi}}} \nabla \xi^{\prime}=0$

The second and third terms in Eq. (7) can be regarded as the response to the anomalous RWS (Rodwell and Jung 2008). These two terms should cancel each other in those regions where the anomalous RWS is very small.

\section{References}

Ambrizzi T, Hoskins BJ, Hsu HH (1995) Rossby wave propagation and teleconnection patterns in the austral winter. J Atmos Sci $52: 3661-3672$ 
Ashfaq M, Skinner CB, Diffenbaugh NS (2011) Influence of SST biases on future climate change projections. Clim Dyn 36:1303-1319

Barimalala R, Bracco A, Kucharski F (2012) The representation of the South Tropical Atlantic teleconnection to the Indian Ocean in the AR4 coupled models. Clim Dyn 38:1147-1166

Bentsen M, Bethke I, Debernard JB, Iversen T, Kirkevåg A, Seland Ø, Drange H, Roelandt C, Seierstad IA, Hoose C, Kristjánsson JE (2012) The Norwegian earth system model, NorESM1-M-part 1: description and basic evaluation. Geosci Model Dev Discuss 5:2843-2931

Bjerknes J (1969) Atmospheric teleconnections from the equatorial pacific. Mon Weather Rev 97:163-172

Carton JA, Huang BH (1994) Warm events in the Tropical Atlantic. J Phys Ocean 24:888-903

Carton JA, Cao X, Giese BS, Da Silva AM (1996) Decadal and interannual SST variability in the Tropical Atlantic Ocean. J Phys Ocean 26:1165-1175

Cassou C, Terray L, Phillips AS (2005) Tropical Atlantic influence on European heat waves. J Clim 18:2805-2811

Chang P, Yamagata T, Schopf P, Behera SK, Carton J, Kessler WS, Meyers G, Qu T, Schott F, Shetye S, Xie SP (2006) Climate fluctuations of tropical coupled systems-the role of ocean dynamics. J Clim 19:5122-5174

Chiang JCH, Lintner BR (2005) Mechanisms of remote tropical surface warming during El Niño. J Clim 18:4130-4149

Chung CTY, Power SB, Arblaster JM, Rashid HA, Roff GL (2014) Nonlinear precipitation response to El Niño and global warming in the Indo-Pacific. Clim Dyn 42:1837-1856

Della-Marta PM, Haylock MR, Luterbacher J, Wanner H (2007) Doubled length of western European summer heatwaves since 1880. J Geophys Res Atmos 112:D15103

Ding H, Keenlyside N, Latif M (2012) Impact of the equatorial Atlantic on the El Niño souther osicllation. Clim Dyn 38:1965-1972

Dufresne JL et al (2013) Climate change projections using the IPSLCM5 earth system model: from CMIP3 to CMIP5. Clim Dyn 40:2123-2165. doi:10.1007/s00382-012-1636-1

Garcia-Serrano J, Losada T, Rodríguez-Fonseca B (2011) Extratropical atmospheric response to the Atlantic Niño decaying phase. J Clim 24:1613-1625

Gent PR et al (2011) The community climate system model version 4. J Clim 24:4973-4991. doi:10.1175/2011JCLI4083.1

Giannini A, Saravanan R, Chan P (2004) The preconditioning role of Tropical Atlantic variability in the development of the ENSO teleconnection: implications for the prediction of Nordeste rainfall. Clim Dyn 22:839-855

Giannini A, Saravanan R, Chan P (2005) Dynamics of the boreal summer African monsoon in the NSIPP1 atmospheric model. Clim Dyn 25:517-535

Giorgetta MA et al (2013) Climate and carbon cycle changes from 1850 to 2100 in MPI-ESM simulations for the Coupled Model Intercomparison Project phase 5. J Adv Model Earth Syst 5:572597. doi:10.1002/jame. 20038

Herceg Bulic I, Brankivic C, Kucharski F (2012) Winter ENSO teleconnections in a warmer climate. Clim Dyn 38:1593-1613

Hoskins BJ, Ambrizzi T (1993) Rossby wave propagation on a realistic longitudinally varying flow. J Atmos Sci 50:1661-1671

Hoskins BJ, Karoly DJ (1981) The steady linear response of a spherical atmosphere to thermal and orographic forcing. J Atmos Sci 38:1179-1196

IPCC (2013) Climate change 2013: The physical science basis. Contribution of working group I to the Fifth Assessment Report of the Intergovernmental Panel on Climate Change. In: Stocker TF, Qin D, Plattner G-K, Tignor M, Allen SK, Boschung J, Nauels A, Xia Y, Bex V, Midgley PM (eds.) Cambridge University Press, Cambridge, United Kingdom and New York (http://www.ipcc.ch/ report/ar5/)
Janicot S, Harzallah A, Fontaine B, Moron V (1998) West African monsoon dynamics and eastern equatorial Atlantic and Pacific SST anomalies (1970-88). J Clim 11:1874-1882

Jansen MF, Dommenget D, Keenlyside NS (2009) Tropical atmosphere-ocean interactions in a conceptual framework. J Clim 22:550-567

Keenlyside NS, Latif M (2007) Understanding equatorial Atlantic interannual variability. J Clim 20:131-142

Keenlyside NS, Ding H, Latif M (2013) Potential of equatorial Atlantic variability to enhance El Niño prediction. Geophys Res Lett 40:2278-2283. doi:10.1002/grl.50362

Kucharski F, Bracco A, Yoo JH, Molteni F (2007) Low-frequency variability of the Indian monsoon-ENSO relationship and the Tropical Atlantic: the "Weakening" of the 1980s and 1990s. J Clim 20:4255-4266

Kucharski F, Bracco A, Yoo JH, Molteni F (2008) Atlantic forced component of the Indian monsoon interannual variability. Geophys Res Lett 35:L04706. doi:10.1029/2007GL033037

Kucharski F, Bracco A, Yoo JH, Molteni F (2009) A Gill-Matsunotype mechanism explains the Tropical Atlantic influence on African and Indian monsoon rainfall. Q J R Meteorol Soc 135:569-579

Kucharski F, Kang IS, Farneti R, Feudale L (2011) Tropical Pacific response to 20th century Atlantic warming. Geophys Res Lett 38:L03702. doi:10.1029/2010GL046248

Losada T, Rodríguez-Fonseca B, Janicot S, Gervois S, Chauvin F, Ruti P (2010a) A multi-model approach to the Atlantic Equatorial mode: impact on the West African monsoon. Clim Dyn 35:29-43

Losada T, Rodríguez-Fonseca B, Polo I, Janicot S, Gervois S, Chauvin F, Ruti P (2010b) Tropical response to the Atlantic Equatorial mode: AGCM multimodel approach. Clim Dyn 35:45-52

Losada T, Rodríguez-Fonseca B, Kucharski F (2012) Tropical influence on the summer Mediterranean climate. Atmos Sci Lett 13:36-42

Lübbecke JF, McPhaden MJ (2013) A comparative stability analysis of Atlantic and Pacific Niño modes. J Clim 26:5965-5980

Martin GM et al (2011) The HadGEM2 family of met office unified model climate configurations. Geosci Model Dev 4:723-757. doi:10.5194/gmd-4-723-2011

Martín-Rey M, Polo I, Rodríguez-Fonseca B, Kucharski F (2012) Changes in the interannual variability of the Tropical Pacific related to the equatorial Atlantic. Sci Mar 76:105-116. doi:10.3989/scimar.03610.19A

Mitchel TD, Jones PD (2005) An improved method of constructing a database of monthly climate observations and associated highresolution grids. Int J Climatol 25:693-712

Mohino E, Rodríguez-Fonseca B, Losada T, Gervois S, Janicot S, Bader J, Ruti P, Chauvin F (2011) Changes in the intereannual SST-forced signals on West African rainfall. AGCM intercomparison. Clim Dyn 37:1707-1725

Molteni F (2003) Atmospheric simulations using a GCM with simplified physical parametrizations. I: model climatology and variability in multi-decadal experiments. Clim Dyn 20:175-191

Patricola CM, Cook KH (2011) Sub-Saharan Northern African climate at the end of the twenty-first century: forcing factors and climate change processes. Clim Dyn 37:1165-1188

Polo I, Rodríguez-Fonseca B, Losada T, García-Serrano J (2008) Tropical Atlantic variability modes (1979-2002). Part I: timeevolving SST modes related to West African precipitation. J Clim 21:6457-6475

Qin J, Robinson WA (1993) On the Rossby wave source and the steady linear response to tropical forcing. J Atmos Sci 50:1819-1823

Rauscher SA, Kucharski F, Enfield DB (2011) The role of regional SST warming variations in the drying of meso-America in future climate projections. J Clim 24:2003-2016 
Rayner NA, Parker DE, Horton EB, Folland CK, Alexander LV, Rowell DP (2003) Global analyses of sea surface temperature, sea ice, and night marine air temperature since the nineteenth century. J Geophys Res. doi:10.1029/2002JD002670

Richter I, Xie SP (2008) On the origin of the equatorial Atlantic biases in coupled general circulation models. Clim Dyn 31:587-598

Richter I, Xie SP, Wittenberg AT, Masumoto Y (2012) Tropical Atlantic biases and their relation to surface wind stress and terrestrial precipitation. Clim Dyn 38:985-1001

Richter I, Xie SP, Behera SK, Doi T, Masumoto Y (2014) Equatorial Atlantic variability and its relation to mean state biases in CMIP5. Clim Dyn 42:171-188

Rodriguez-Fonseca B, Polo I, Garcia-Serrano J, Losada T, Mohino E, Mechoso CR, Kucharski F (2009) Are Atlantic Ninos enhancing Pacific ENSO events in recent decades? Geophys Res Lett 36:L20705. doi:10.1029/2009GL040048

Rodwell MJ, Jung T (2008) Understanding the local and global impacts of model physics changes: an aerosol example. Q J R Meteorol Soc 134:1479-1497

Rotstayn LD, Jeffrey SJ, Collier MA, Dravitzki SM, Hirst AC, Syktus JI, Wong KK (2012) Aerosol-and greenhouse gas-induced changes in summer rainfall and circulation in the Australasian region: a study using single-forcing climate simulations. Atmos Chem Phys 12:6377-6404. doi:10.5194/acp-12-6377-2012

Sardeshmukh PD, Hoskins BJ (1988) The generation of global rotational flow by steady idealized tropical divergence. J Atmos Sci 45:1228-1251

Schmidt GA et al (2014) Configuration and assessment of the GISS ModelE2 contributions to the CMIP5 archive. J Adv Model Earth Syst 6:141-184. doi:10.1002/2013MS000265

Stockdale TN, Balmaseda M, Vidard A (2006) Tropical Atlantic SST prediction with coupled ocean-atmosphere GCMs. J Clim 18:6047-6061

Sud YC, Walker GK, Lau KM (1999) Mechanisms regulating SeaSurface temperatures and deep convection in the tropics. Geophys Res Lett 26:1019-1022
Taylor KE, Stouffer RJ, Meehl GA (2011) An overview of CMIP5 and the experiment design. BAMS 93:485-498

Vizy EK, Cook KH (2002) Development and application of a mesoscale climate model for the tropics: influence of sea surface temperature anomalies on the West African monsoon. J Geophys Res. doi:10.1029/2001JD000686

Voldoire A, Sanchez-Gomez E et al (2013) The CNRM-CM5.1 global climate model: description and basic evaluation. Clim Dyn 40:2091-2121. doi:10.1007/s00382-011-1259-y

Volodin EM, Dianskii NA, Gusev AV (2010) Simulating present day climate with the INMCM4.0 coupled model of the atmospheric and oceanic general circulations. Izv Atmos Ocean Phys 46:414-431

Wang C, Lee SK, Enfield DB (2008) Climate response to anomalously large and small Atlantic warm pools during the summer. J Clim 21:2437-2450

Wang C, Zhang L, Lee SK, Wu L, Mechoso CR (2014) A global perspective on CMIP5 climate model biases. Nat Clim Change 4:201-205

Watanabe S, Hajima T, Sudo K et al (2011) MIROC-ESM 2010: model description and basic results of CMIP5-20c3 m experiments. Geosci Model Dev 4:845-872. doi:10.5194/ gmd-4-845-2011

Wilks DS (2005) Statistical methods in the atmospheric sciences. Elsevier, San Diego

Yukimoto et al (2011) Meteorological Research Institute-Earth System Model Version 1 (MRI-ESM1)—model description. Technical report of the Meteorological Research Institute, 64, 83

Zebiak SE (1993) Air-sea interaction in the equatorial Atlantic region. J Clim 6:1567-1586

Zhang C (1993) Large-scale variability of atmospheric deep convection in relation to sea surface temperatures in the tropics. J Clim 6:1898-1913 